\title{
1 LIGHT- AND CLOCK-CONTROL OF GENES INVOLVED IN DETOXIFICATION
}

2 G. Carmona-Antoñanzas ${ }^{1}$, M. Santi ${ }^{1,2}$, H. Migaud ${ }^{1}$ and L.M. Vera ${ }^{1}$

$3 \quad{ }^{1}$ Institute of Aquaculture, Faculty of Natural Sciences, University of Stirling, FK9 4LA, Stirling, UK

$4 \quad{ }^{2}$ Life and Environmental Sciences Department, Marche Polytechnic University, 60121, Ancona, Italy

5

6 Corresponding author:

7 Dr. L.M. Vera

8 Institute of Aquaculture

$9 \quad$ University of Stirling, FK9 4LA, UK

$10 \quad$ Tel: $+44-1786-466573$

11 E-mail:luisa.veraandujar@stir.ac.uk

12

13

14

Running head: Detoxification rhythms in zebrafish

15

16

17

18

19

20

21

22

23 
ABSTRACT

Circadian regulation of hepatic detoxification seems to be amongst the key roles of the biological clock. The liver is the major site for biotransformation, and in mammals, it contains several clock-controlled transcription factors such as PAR basic leucine zipper proteins (bZIP) and basic-helix-loop-helix (bHLH)-PAS family that act as circadian regulators of detoxification genes. This investigation explored the existence of daily and circadian expression of transcription factors involved in detoxification, as well as the temporal profile of a set of their target genes in zebrafish liver. In our study, zebrafish were able to synchronize to a light-dark (LD) cycle and displayed a diurnal pattern of activity. In addition, the expression of clock genes presented daily and circadian rhythmicity in liver. Apart from $h l f a$, the expression of PAR bZIP transcription factors also displayed daily rhythms, which appeared to be both light-dependent and clock-controlled, as circadian rhythms free-ran under constant conditions (continuous darkness, DD). Under LD, tefb, dbpa and $d b p b$ expression peaked at the end of the darkness period whereas tefa showed peak levels of expression at the onset of the photophase. In addition, these four genes exhibited circadian expression under DD, with higher expression levels at the end of the subjective night. The expression of the bHLH-PAS transcription factor arh2 also showed circadian rhythmicity in zebrafish liver, peaking in the middle of the subjective night and approximately 3-4 hours before peak expression of the PAR bZIP genes. Regarding the detoxification genes, the major target gene of AhR, cypla, showed daily and circadian expression with an acrophase 2 hours after $a h r 2$. Under LD, abcb4 also showed daily rhythmicity, with an acrophase 1-2 $\mathrm{h}$ after that of PAR bZIP factors during the transition between darkness and light phases, when zebrafish become active. However, the expression of six detoxification genes showed circadian rhythmicity under DD, including cypla and $a b c b 4$ as well as gstr1, mgst3a, abcg2 and sult2_st2. In all cases, the acrophases of these 

transcription factors. This suggested that their expression is clock-controlled, either directly by core clock genes or through transcription factors. This study presents new data

53 demonstrating that the process of detoxification is under circadian control in fish. Results

54 showed that time of day should be considered when designing toxicological studies or 55 administering drugs to fish.

56

57 Keywords: Zebrafish, liver, circadian, PAR bZIP, bHLH-PAS, detoxification genes. 
All vertebrates show rhythmic regulation of most of their biological functions, which enable them to adapt to daily environmental cycles generated by the Earth's rotation (e.g. day/night alternation, temperature) and food availability. The existence of endogenous clocks allows animals to anticipate cyclic events and consequently perform biological activities at the most suitable times throughout the day or the year (Mazzoccoli et al., 2012). As in other vertebrates, the molecular circadian clock in fish involves two interlocked negative feedback loops of clock genes and proteins that drive the rhythmic expression of a wide set of genes, leading to overt cycles in physiology and behavior (Dibner \& Schibler, 2015). Natural toxins and other harmful compounds are mainly found in food, so circadian regulation of xenobiotic detoxification is a key function of the biological clock (Claudel et al., 2007). Previous investigations in mice have suggested that the circadian clock is involved in the timedependent drug toxicity, as an anticancer agent (cyclophosphamide) was found to be more toxic to mice with a null allele of Bmall or a mutation of the Clock gene, whereas animals lacking both copies of Cry were more resistant (Gorbacheva et al., 2005).

The liver is the core organ involved in nutrient metabolism and detoxification, processes that are adjusted in a timely manner, allowing the organisms to adapt and meet the demands of changing environmental conditions. In mammals, detoxification seems to be subjected to circadian regulation (de Wit et al., 2014). Hepatic detoxification includes multiple biochemical processes that convert lipophilic toxins into water-soluble metabolites that can be efficiently eliminated from the body via the urine (Grant, 1991). This protective ability stems from the expression of a variety of xenobiotic biotransforming enzymes with the ability to catalyze the oxidation, reduction and hydrolysis (Phase I) and/or conjugation (Phase II) to make them hydrophilic and excretable by transporter proteins in phase III (Reinke \& Asher, 
and aldehyde dehydrogenases, which in mice are regulated by the circadian clock and show peak levels of expression during the active phase of the animals, when they are more likely to be exposed to xenobiotics (i.e. at night) (Zhang et al., 2009). Previous research has also found diurnal rhythmicity in phase II conjugating glutathione-S-transferases and phase III transporters, including ATP-binding cassette transporter (ABC transporters) and metallothionein, although daily patterns vary between protein families (Pedrini-Martha et al., 2016; Zhang et al., 2009). Phase II enzymes also include other transferases such as sulfotransferases and nonconjugation enzymes, i.e. quinone reductase and epoxide hydrolase (Chen, 2012). In addition, biotransformation of xenobiotics may increase the production of reactive oxygen species (ROS), which are neutralized by antioxidant enzymes such as catalase, glutathione peroxidase, glutathione reductase and superoxide dismutase (Ribalta et al., 2015).

In mammals, the liver-specific PAR basic leucine zipper proteins (bZIP), thyrotroph embryonic factor (TEF), albumin D box-binding protein (DBP) and hepatic leukemia factor (HLF) act as circadian regulators of numerous genes involved in the metabolism of endobiotic and xenobiotic substances and, in turn, are transcriptionally regulated by core oscillator components (Gachon et al., 2006). Once activated, hepatic transcription factors trigger target gene expression by binding to response elements within regulatory regions of detoxification enzymes and nuclear receptors. This is the case for the constitutive androstane receptor (CAR) and the aryl hydrocarbon receptor (AhR), which are known to be xenobiotic sensors directly involved in the transcriptional regulation of numerous phase I and II enzymes, as well as transporter proteins that play a key role in the elimination of toxicants (Košir et al., 2013; Nakata et al., 2006). The AhR, which forms part of the basic-helix-loophelix (bHLH)-PAS family, dimerizes with the Ahr nuclear translocator (ARNT) thereby 
triggering toxicological response upon activation by halogenated and polycyclic aromatic hydrocarbons (i.e. dioxins) (Claudel et al., 2007).

In zebrafish, clock systems have been reported to be directly photosensitive and entrainable by the light-dark (LD) cycle (Whitmore et al., 2000) and, in fact, comparison of the promoter regions of these light-inducible genes has revealed the existence of D-box enhancer elements that are activated by the PAR bZIP family (Idda et al., 2012; Vatine et al., 2009). Previous research has investigated the spatial expression pattern of PAR bZIP genes in zebrafish embryo, showing higher expression in cranial areas. In addition, rhythmic gene expression was detected in the pineal gland, including both clock-controlled and light-dependent expression patterns (Ben-Moshe et al., 2010). However, the daily (under an LD cycle) and circadian (in the absence of environmental cues) rhythmicity of this family of transcription factors and the detoxification enzymes regulated by them have not yet been investigated in the liver of zebrafish, although clear evidence is pointing at their key role in the circadian regulation of xenobiotic detoxification in mammals, including the metabolism of therapeutic drugs (Gachon, 2007; Gachon \& Firsov, 2011). Therefore, the administration time can affect the tolerance and efficiency of such drugs in vertebrates, including fish species.

Despite studies showing daily rhythms of toxicity in zebrafish (Sánchez-Vázquez et al., 2011), insight into the molecular mechanisms driving this rhythmicity was still lacking. Thus, the aim of the present study was to demonstrate light- and clock-controlled expression patterns of transcription factors mediating the circadian regulation of detoxification together with the temporal profile of a set of their target genes in zebrafish liver.

\section{MATERIALS AND METHODS}

\section{Animals \& housing}


A total of 843 -month old wild-type $\mathrm{AB}$ mixed-sex zebrafish $(0.42 \pm 0.13 \mathrm{~g}$ body weight $)$ were obtained from the University College of London Fish Facility (London, UK) and housed in an isolated fish laboratory at the Institute of Aquaculture of the University of Stirling (Stirling, UK). Experimental fish were randomly allocated to twelve $11 \mathrm{~L}$ plastic tanks $(35.6$ x 23.4 x $22.8 \mathrm{~cm})($ Geo Extra Large Tank, Ferplast, Italy) (n=7 fish/tank), each one equipped with an individual filter (PF Mini Internal Power Filter, Interpet, UK) and supplied with filtered and dechlorinated tap water. During the acclimation period, the photoperiod was set at $12 \mathrm{~h}: 12 \mathrm{~h}$ light-dark (LD) and temperature was kept constant at $25^{\circ} \mathrm{C}$ throughout the trial using water heaters (H2 Therm 15W Micro Aquarium Heater, Tropical Marine Centre, UK). Fish were hand-fed once a day ad libitum a commercial diet (Otohime B2 360-650 $\mu \mathrm{M}$, Marubeni Nisshin Feed Co., Ltd., Japan) at random times during daytime over a two-week acclimation period and during the trial. The walls of all aquaria were covered with black plastic sheets to prevent different groups of animals from seeing each other.

\section{Experimental design}

The experimental procedure complied with the Guidelines of the European Union (2010/63/UE) and the Animal (Scientific Procedures) Act 1986 UK under the approval of the Animal Welfare and Ethical Review Body (AWERB) of the University of Stirling. In addition, the experimental design and methodology followed in this investigation were in accordance with the international ethical standards of Chronobiology International (Portaluppi et al., 2010).

To investigate daily and circadian rhythms of locomotor activity and gene expression, zebrafish were initially kept under a 12:12 h LD cycle. Throughout the experiment, the existence of a daily activity rhythm and its synchronization to the LD cycle was monitored. To this end, locomotor activity was recorded by an infrared photocell (E3Z-D67, Omron, 
173 Kyoto, Japan) placed in each tank, $11 \mathrm{~cm}$ away from the bottom and $7 \mathrm{~cm}$ away from the 174 lateral wall. The photocells were connected to a computer, and every time a fish interrupted 175 the infrared light beam, it produced an output signal that was recorded and stored in 10 176 minutes bins using specialized software (DIO98USB, University of Murcia, Spain).

177 To investigate daily rhythms of gene expression in LD, after a two-week period, 42 fish 178 ( $\mathrm{n}=7 / \operatorname{tank}, 6$ tanks) were fasted for one day and then sacrificed by lethal anaesthesia (2phenoxyethanol, $1 \mathrm{~mL} / \mathrm{L}$, Sigma) every $4 \mathrm{~h}$ during a $24 \mathrm{~h}$ period, at "Zeitgeber Times" (ZT) 2, 6, 10, 14, 18 and 22 (1 tank/ZT). Liver samples were obtained from each fish and preserved in RNALater® (Sigma-Aldrich, Poole, UK). In darkness conditions, sampling was performed using dim red light attached to the dissecting microscope.

To determine the existence of circadian rhythms of gene expression, the remaining 42 experimental fish ( $\mathrm{n}=7 / \operatorname{tank}, 6$ tanks) were kept under an LD cycle for an additional week and then lights were switched off at ZT0. Fish were fasted and kept in continuous darkness (DD) for $24 \mathrm{~h}$ and then sampled, starting at circadian time (CT) 2 (onset of the subjective day). Samples were obtained every $4 \mathrm{~h}$ during a $24 \mathrm{~h}$ cycle (at CT2, 6, 10, 14, 18 and 22). From each fish, liver samples were also collected in RNALater®.

\section{Gene expression}

Liver samples were homogenized in $1 \mathrm{~mL}$ of TRIzol® (Invitrogen, UK) and total RNA extracted in accordance with the manufacturer's instructions. RNA pellets were rehydrated in DNase RNase-free distilled water (Merck Millipore) and total RNA concentration determined using an ND-1000 Nanodrop spectrophotometer (Labtech Int., East Sussex, UK). RNA integrity was assessed by agarose gel electrophoresis. 
arh2) and 16 detoxification genes (smtb, mt2, sod1, cypla, cypld1, cat, gpx7, gsr, gstt2, gstt1a, gstr1, mgst3a, abcb4, abcc2, abcg2, sult2_st2) (Table 1) (S1 Table). The software PRIMER3 (Untergasser et al., 2012) was used to design new sets of primers and their target specificity was checked in silico using Blast (NCBI) (Table 1). cDNA was reverse transcribed from $1 \mu \mathrm{g}$ of total RNA using QuantiTect Reverse Transcription kit (Qiagen Ltd., Manchester, UK). The resulting cDNA was diluted 20-fold with Milli Q water and $2.5 \mu \mathrm{L}$ of each sample was used in combination with $300 \mathrm{nM}$ of each primer and $5 \mu \mathrm{L}$ of Luminaris Color HiGreen qPCR Master mix (Thermo Fisher Scientific, MA, USA) to reach a final PCR volume of $10 \mu \mathrm{L}$. Reactions were run in a Mastercycler RealPlex 2 thermocycler (Eppendorf, UK) programmed to perform the following protocol: UDG pre-treatment at $50{ }^{\circ} \mathrm{C}$ for $2 \mathrm{~min}$ preceded thermal cycling, which was initiated at $95{ }^{\circ} \mathrm{C}$ for $10 \mathrm{~min}$, followed by 40 cycles with a denaturing step at $95{ }^{\circ} \mathrm{C}$ for $15 \mathrm{~s}$, annealing for $30 \mathrm{~s}$ at Ta according to Table 1 and extension at $72^{\circ} \mathrm{C}$ for $15 \mathrm{~s}$. The amplification cycle was followed by a temperature ramp with $0.5^{\circ} \mathrm{C}$ increments ranging between $60{ }^{\circ} \mathrm{C}$ and $90{ }^{\circ} \mathrm{C}$ for melt-curve analysis to verify that no primer-dimer artefacts were present and only one product was generated from each qPCR assay. Amplifications were carried out including systematic negative controls containing no cDNA (NTC, no template control) and omitting reverse transcriptase enzyme (-RT) to check for DNA contamination. In addition, the qPCR product sizes were checked by agarose gel electrophoresis and the identity of random samples was confirmed by sequencing (GATC Biotech, Germany). No primer-dimer occurred in the NTC. Gene expression quantification was achieved by including a parallel set of reactions containing serial dilutions from all pooled cDNA experimental samples and assigning each dilution the appropriate value of relative units (RUs). As a result, an estimated number of relative copies, corrected for the efficiency of the reaction, was automatically calculated for each sample. 


\section{Data analysis}

224 The locomotor activity displayed by fish during the experiment was analyzed by a 225 chronobiology software (El Temps ${ }^{\odot}$ v.1.179, Dr. Díez-Noguera, Barcelona, Spain).

226 The normalized expression values were generated by the $\Delta \mathrm{Ct}$ method (Pfaffl, 2001) and the

227 results expressed as mean normalized ratios $( \pm \mathrm{SE})$ between the RUs of target genes and a reference gene index calculated from the geometric mean of the two most stable reference genes (i.e. ribosomal protein L3, rpll3 and solute carrier family 25a, slc25a). Housekeeping gene stability (S2 Table) was determined applying a correction for efficiency to the raw $\mathrm{Ct}$ standard deviation (Pfaffl, 2004) using RefFinder (Xie et al., 2012).

Statistical differences in gene expression between different sampling times were analyzed by one-way ANOVA (ANOVA I), followed by Tukey's post hoc test, using SPSS v.19 software (IBM, Armonk, NY). Cosinor analysis was performed using Ritme software (Antoni DíezNoguera, University of Barcelona, Spain) to determine whether the daily expression of the studied genes fitted the cosine function: $Y=M+A^{*}[\operatorname{Cos}(\Omega t+\Phi)]$, where $M$ is mesor, $A$ is amplitude, $\Omega$ is angular frequency $\left(360^{\circ} / 24 \mathrm{~h}\right.$ for the circadian rhythms) and $\Phi$ is acrophase. The significance level was fixed at $p<0.05$ for all the statistical analysis.

\section{RESULTS}

\section{Locomotor activity}

242 Zebrafish kept under an LD cycle showed a diurnal activity pattern, with 80-95\% of their 243 total swimming activity displayed during the day. Activity levels sharply increased at the beginning of the day and in most experimental tanks continued to increase gradually during the first $4 \mathrm{~h}$ of the photophase. In other cases activity levels were sustained during the photophase after lights onset. When lights switched off, activity decreased abruptly in all tanks (Fig. 1). 


\section{Clock genes}

250 Under LD, the expression of all clock genes investigated in the liver of zebrafish showed 251 significant differences during the $24 \mathrm{~h}$ cycle (ANOVA I, p<0.05) and daily rhythmicity, as 252 revealed by cosinor analysis $(\mathrm{p}<0.05)$. The daily rhythms of bmalla and clockla were in 253 phase with their acrophases only two hours apart, at ZT=11:11 and ZT=13:31 (Table 2), 254 respectively, whereas the expression of cryla and per2 peaked during the first half of the day, 255 in antiphase to bmalla and clockla (Fig. 2A).

256 In the absence of external zeitgebers (DD), the expression of all clock genes showed 257 circadian rhythmicity (Fig. 2B), with acrophases within two hours apart from those observed under LD (Table 2).

\section{Transcription factors}

261

All PAR bZIP transcription factors except $h l f a$ showed daily and circadian rhythmicity in zebrafish liver (Fig. 3). Under LD, the acrophases of tefb, $d b p a$ and $d b p b$ expression were located in the second half of the night phase (ZT between 21:32-22:58) whereas tefa expression peaked at the beginning of the day $(\mathrm{ZT}=01: 19)$. Under $\mathrm{DD}$, the acrophases of all the rhythmic PAR bZIP transcription factors were located around CT23 (Table 3).

No daily rhythmicity of $a h r 2$ expression or significant differences between time points were observed in zebrafish exposed to LD. However, cosinor analysis revealed the existence of circadian rhythmicity in fish exposed to DD (acrophase at CT19:23; Table 3).

\section{Detoxification genes}

Under LD, two detoxification genes showed a daily rhythm of expression (cosinor, $\mathrm{p}<0.05$ ), cypla and $a b c b 4$, with their acrophases located at $\mathrm{ZT}=21: 30$ and $\mathrm{ZT}=00: 03$, respectively 
(Table 4). In addition, smtb expression displayed significant statistical differences between time points, peaking at ZT2 (ANOVA I, p<0.05) (Fig. 4), although a daily rhythm could not be fitted neither in LD nor DD. On the other hand, cosinor analysis in DD revealed that the transcript expression of six detoxification genes followed circadian rhythmicity $(\mathrm{p}<0.05)$, including cypla and $a b c b 4$ (as in LD), as well as gstr1, mgst3a, abcg2 and sult2_st2 (Fig. 5 and 6). In all cases, the acrophases of these genes peaked during the second half of the night, between CT20-23, in phase with the PAR bZIP transcription factors (Table 4, Fig. 7). Gene expression was also determined from detoxification genes including sodl, cypld1, cat, gpx7, gsr, gstt2, gstt1a, abcc2 and $m t 2$; however, no circadian rhythmicity or circadian-control were detected (S3 Fig.).

\section{DISCUSSION}

The present study showed that zebrafish displayed a diurnal pattern of activity and were able to synchronize to the LD cycle, in accordance with previous behavioural studies carried out in this species (Del Pozo et al., 2011; Hurd et al., 1998). Overall, the expression of clock genes showed daily and circadian rhythms in agreement with results previously reported in zebrafish and other teleost species (Boyle et al., 2017; Cahill, 2002; Li et al., 2013; Vera et al., 2013). Only the results obtained for per2 differed from previous research (Cahill, 2002; Vatine et al., 2009), which showed that the expression of this gene was exclusively regulated by light. In the present study, per 2 displayed circadian rhythmicity in $\mathrm{DD}$, as observed in Sparus aurata (Vera et al., 2013), suggesting that the expression of this clock gene in liver may not be exclusively light-regulated, although the amplitude of the rhythm in DD was much lower than under LD. In addition, the present study provided new evidence on the circadian regulation of detoxification mechanisms in zebrafish, revealing that both detoxification genes and key transcription factors regulating their expression displayed 
rhythmicity. Recent research in fish demonstrated the chronotoxicity of anaesthetics (Sánchez-Vázquez et al., 2011; Vera et al., 2010; Vera et al., 2013b) and aquaculture medicines (Vera \& Migaud, 2016). However, the molecular mechanisms underlying the temporal variations in toxicity and/or effectiveness of these compounds remained unclear.

In the last few decades, the circadian regulation of xenobiotic and endobiotic detoxification has been widely investigated in mammals, with studies revealing that the circadian clock regulates daily differences in toxicity, either directly or through clock-controlled transcription factors, such as PAR bZIP proteins and nuclear receptors which drive the expression of many detoxifying enzymes. In zebrafish liver, the expression of most PAR bZIP transcription factors showed daily rhythmicity, in tune with the clock genes, which appeared to be both light-dependent (under an LD cycle) and clock-controlled, as circadian rhythms persisted in the absence of external cues (DD) for 26-44 h (CT2-CT22, respectively). The hepatic expression profiles of tefb, $d b p a$ and $d b p b$ were in phase and peaked at the end of the darkness period in LD and at the end of the subjective night in DD, which is in accordance with results obtained in the pineal organ of zebrafish embryo (Ben-Moshe et al., 2010). On the other hand, microarray analysis in zebrafish liver identified the acrophase of tefb and $d b p b$ at the beginning of the light phase, altough in this case fish had been kept in a $14 \mathrm{~h}: 10 \mathrm{~h}$ LD cycle (Boyle et al., 2017). In addition, dbpa expression was found arrythmic, in contrast with our results. Regarding tefa, the present study identified maximum levels of expression in the beginning of the light phase in LD, two hours before the acrophase reported by Boyle et al. (2017). With respects to hlfa expression, we did not observe time-of-day variation in contrast with the study by Ben-Moshe et al. (2010) but in accordance to results by Boyle et al. (2017). Vatine et al. (2009) reported an increase of tef mRNA levels following exposure to light under LD and at the beginning of the subjective day in DD and concluded that tef is upregulated predominantly by light and partially by the circadian clock. Moreover, Li et al. 
(2013) found that tefa is a fast light-induced transcription factor in zebrafish, showing a peak of expression around $4 \mathrm{~h}$ after light onset. Other studies have also observed that the acrophase of tef expression preceded that of per2, another fast light-induced gene, which suggested that TEF may be a regulatory factor contributing to the light-driven expression of per2. In order to test this hypothesis, knock-down experiments were carried out, demonstrating that TEF mediates per2 light-induction. In our study, the daily rhythm of tefa expression peaked around $4 \mathrm{~h}$ before per2, which is in accordance with previous findings (Vatine et al., 2009). In fact, regulation of PAR bZIP factors by the core clock has been demonstrated in mammals, showing that CLOCK/BMAL1 heterodimer regulates the rhythmic expression of Dbp by Ebox-mediated transcription (Ripperger et al., 2000; Ripperger \& Schibler, 2006). In rat, a nocturnal species, $D p b$ expression is barely detectable during the early morning hours; however, its expression increases during the afternoon and reaches maximal levels at the end of the day, just before the active phase of the animal (Wuarin \& Schibler, 1990). Similarly, in diurnal zebrafish, a peak of expression for both $d b p a$ and $d b p b$ was observed at the end of the night period, just preceding their active diurnal phase. According to Li et al. (2013), the timelag between the acrophases of transcription factors involved in circadian regulation and that of their target genes can vary from immediate up to 12 hours. Furthermore, additional phases can be generated by transcription factors regulated by core circadian genes. Indeed, the generation of diverse circadian phases in gene expression is critical as different metabolic processes require activation at different times to optimize physiological functions (Dibner \& Schibler, 2015). In our study, the hepatic expression of PAR bZIP genes showed the acrophase between $11 \mathrm{~h}$ and $14 \mathrm{~h}$ later than bmalla and clockla in both LD and DD, which is in accordance with the circadian gene regulatory cascade described before in zebrafish larvae (Li et al., 2013). 
Under DD, the expression of the nuclear receptor arh2 also showed circadian rhythmicity in zebrafish liver, with peak levels detected in the middle of the subjective night, corresponding to the resting phase of zebrafish, and 3-4 hours before the PAR bZIP acrophases. Similarly, the expression of $A h R$ showed a daily rhythm in rat liver, showing a peak in the middle of the day, during the resting phase of this nocturnal species (Richardson et al., 1998). AhR is located in the cytoplasm, but after binding to a ligand (i.e. xenobiotic), it is activated and translocated to the nucleus where it dimerizes with ARNT. This complex binds to the xenobiotic responsive element (XRE) region of a number of detoxification genes and activates their transcription, including phase I and II enzymes. In particular, the major target gene of AhR is Cypla which also displays circadian rhythmicity in rat (Huang et al., 2002). In our study, cypla showed daily and circadian expression in zebrafish liver, with the acrophases located at ZT21:30 and CT21:58, respectively in LD and DD, approximately 2 hours later than arh2. This suggests that this gene may also be involved in the activation of cypla expression in this species. In addition, as in the PAR bZIP genes, an E-box element has been identified in the mouse $A h R$ promoter (Garrison \& Denison, 2000). Since this region is a consensus-binding site for CLOCK/BMAL1 heterodimer, it is plausible to assume that $A h r$ expression may be regulated by core clock genes. In zebrafish liver, $a h r 2$ expression peaked 5-9 hours later than clockl and bmall, which is in accordance with this hypothesis, but further studies are required to explore the exact mechanisms involved in the activation of $a h r 2$ transcription.

367 Regarding detoxification genes, only $a b c b 4$ and cypla showed daily rhythmicity in LD, with the acrophase detected 1-3 $\mathrm{h}$ after that of PAR bZIP factors and in the interphase between night and day, just before or at the onset of the active period of zebrafish. Therefore, these detoxification proteins would be more expressed when the risk of exposure to toxicants or the production of metabolic byproducts is higher in this species. Likewise, in mouse liver, $A b c b 4$ 
is involved in the metabolism of cholesterol and shows a peak of expression in the interphase day-night. In addition, further analysis of the hepatic transcriptome of mouse has revealed that a large number of detoxification genes are expressed according to a circadian pattern, with expression peaking just before the active phase of the animal indicating that, as for other physiological functions, the circadian clock allows the organisms to anticipate cyclic environmental events (Gachon \& Firsov, 2011). The ATP-binding cassette (ABC) family is primarily involved in the transport of molecules across the cellular membrane, while only some specific families are responsible to eliminate chemicals from the hepatocytes into bile or blood (Fischer et al., 2013). Thus, rhythmic expression of membrane transporters may play a role in the diurnal transport of nutrients, metabolic substances or toxins present in food (Zhang et al., 2009).

In the present study, six detoxification genes showed circadian variation in expression under DD indicating that their expression is clock-controlled, either directly by core clock genes or through transcription factors, although further studies would be required to determine the robustness of such rhythmicity when zebrafish are kept in constant conditions for a longer period of time. The expression of all the detoxification genes was in phase or slightly advanced to PAR bZIP genes. Nevertheless, in all cases, gene expression reached peak levels at the end of the subjective night, in anticipation to the active period of zebrafish. According to Gachon et al. (2006), PAR bZIP proteins regulate the expression of Phase II and Phase III detoxification genes that include GSTt1, GSTa3 and Abcg2. In zebrafish no significant rhythmicity of gsttla was detected in LD or DD although mgst3a and abcg2 showed circadian expression in DD, with acrophases $2 \mathrm{~h}$ earlier than PAR bZIP genes in agreement with previous results reported in zebrafish liver (Boyle et al., 2017). The fact that the acrophase of detoxification genes occurred earlier than that of PAR bZIP genes could be explained by gene-specific differences in free-running periods in the absence of external 
cues, since multiple independent oscillators have been described in zebrafish (Idda et al., 2012). In addition, gstrl, another gene belonging to the GST (glutathione S-transferase) family, also displayed circadian expression in DD, with the acrophase in phase with $m g s t 3 a$. The expression of detoxification enzymes such as Cypla is regulated by AhR, as mentioned above, whereas other genes involved in xenobiotic metabolism are mostly controlled by CAR, whose circadian expression is driven by PAR bZIP proteins (Gachon et al., 2006). Previous research in fish species revealed that the time of exposure to hydrogen peroxide caused time-dependent differences in the induction of detoxification genes, being higher in the middle of the light phase (Vera \& Migaud, 2016). On the other hand, the exposure of zebrafish to anaesthetics (MS-222 and eugenol) resulted in higher toxicity to fish when trials were carried out in the middle of the light phase (ML) in comparison to mid-darkness (MD) (Sánchez-Vázquez et al., 2011). MS-222 detoxification route involves $\mathrm{N}$-acetylation whereas eugenol metabolism comprises glucuronidation and sulfate conjugation. In the present investigation we did not measure the expression of $\mathrm{N}$-acetylases or glucuronidases; however, the expression of sult2_st2 (a sulfotransferase gene) peaked around the middle of the subjective night in DD which is in accordance with the lower toxicity of eugenol around this time of the day. In the case of bath exposures, as routinely done in the fish industry to treat against parasitic infections, it is important to take into account that the toxic uptake from the water will also vary depending on the activity pattern of the fish and will be higher during the day in diurnal species, thus inducing a more noxious effect at that time, as reported by Vera et al. (2013b).

In conclusion, this study demonstrated that the expression of PAR bZIP and bHLH-PAS transcription factors as well as a number of detoxification genes is under circadian regulation in zebrafish liver. Our findings suggest that core circadian genes, such as bmalla and clockla may control the activation of tefa, tefb, $d b p a, d b p b$ and $a h r 2$ which in turn would be involved 
422 in the transcriptional activation of detoxification genes. Previous research in fish had 423 provided evidence of how toxicological response and the effect of xenobiotics can be

424 influenced by the time of administration. Insight into the basic molecular mechanisms 425 involved in detoxification suggests that such differences are clock-controlled and highlights 426 the importance of considering the time of day when designing toxicological studies or 427 administering drugs to vertebrates. In particular, the zebrafish model is extensively used in 428 the field of toxicology and pharmacology, to test the toxicity of a wide range of chemicals, and has also been established as a model to investigate key aspects of the vertebrate circadian clock. In addition, the use of diurnal zebrafish in biomedical research offers an advantage over nocturnal rodents, making zebrafish a practical and useful model organism when extrapolating results and making comparisons to humans. Therefore, the present investigation contributes to increase our knowledge about circadian regulation of detoxification, a topic that has been scarcely addressed in zebrafish but with strong potential impact on the use of drug therapies in vertebrates, including fish species.

\section{Acknowledgements}

This research was supported by IMPACT Fellowship awarded to L.M. Vera (University of

Stirling). The authors wish to thank Prof. David Whitmore and Carole Wilson from the University College of London (UCL) Fish Facility for their kind help with zebrafish provision.

Declaration of interest: The authors report no conflicts of interest. The authors alone are responsible for the content and writing of the paper.

\section{REFERENCES}


447 Ben-Moshe Z, Vatine G, Alon S, Tovin A, Mracek P, Foulkes NS, Gothilf Y. (2010). 448 Multiple PAR and E4BP4 bZIP transcription factors in zebrafish: Diverse spatial and 449 temporal expression patterns. Chronobiol Int. 27: 1509-31.

450 Boyle G, Richter K, Priest HD, Traver D, Mockler TC, Chang JT, Kay SA, Breton G. (2017). 451 Comparative analysis of vertebrate diurnal/circadian transcriptomes. PLoS One. 12: $452 \mathrm{e} 0169923$.

453 Cahill GM. (2002). Clock mechanisms in zebrafish. Cell Tissue Res. 309: 27-34.

454 Chen, CH. (2012). Activation and detoxification enzymes: functions and implications. New 455 York: Springer.

456 Claudel T, Cretenet G, Saumet A, Gachon F. (2007). Crosstalk between xenobiotics 457 metabolism and circadian clock. FEBS Lett. 581: 3626-33.

458 De Wit AS, Nijman R, Destici E, Chaves I, van der Horst GTJ. (2014). Hepatotoxicity and 459 the Circadian Clock: A Timely Matter. In Kleinjans J ed. Toxicogenomics-based cellular 460 models: alternatives to animal testing for safety assessment. Cambridge: Academic Press, pp. $461 \quad 251-270$.

462 Del Pozo A, Sánchez-Férez JA, Sánchez-Vázquez FJ. (2011). Circadian rhythms of self463 feeding and Locomotor activity in zebrafish (Danio rerio). Chronobiol Int. 28: 39-47.

464 Dibner C, Schibler U. (2015). Circadian timing of metabolism in animal models and humans. 465 J Intern Med. 277: 513-27.

466 Fischer S, Klüver N, Burkhardt-Medicke K, Pietsch M, Schmidt A-M, Wellner P, Schirmer 467 K, Luckenbach T. (2013). Abcb4 acts as multixenobiotic transporter and active barrier 468 against chemical uptake in zebrafish (Danio rerio) embryos. BMC Biol. 11: 69.

469 Gachon F. (2007). Physiological function of PARbZip circadian clock-controlled 470 transcription factors. Ann Med. 39: 562-71.

471 Gachon F, Firsov D. (2011). The role of circadian timing system on drug metabolism and 472 detoxification. Expert Opin Drug Metab Toxicol. 7: 147-58.

473 Gachon F, Olela FF, Schaad O, Descombes P, Schibler U. (2006). The circadian PAR474 domain basic leucine zipper transcription factors DBP, TEF, and HLF modulate basal and 
475 inducible xenobiotic detoxification. Cell Metab. 4: 25-36.

476 Garrison PM, Denison MS. (2000). Analysis of the murine AhR gene promoter. J Biochem 477 Mol Toxicol. 14: 1-10.

478 Gorbacheva VY, Kondratov R V, Zhang R, Cherukuri S, Gudkov A V, Takahashi JS, Antoch 479 MP. (2005). Circadian sensitivity to the chemotherapeutic agent cyclophosphamide depends 480 on the functional status of the CLOCK/BMAL1 transactivation complex. Proc Natl Acad Sci 481 U S A. 102: 3407-12.

482 Grant DM. (1991). Detoxification pathways in the liver. J Inherit Metab Dis. 14: 421-30.

483 Huang P, Ceccatelli S, Rannug A. (2002). A study on diurnal mRNA expression of CYP1A1, 484 AHR, ARNT, and PER2 in rat pituitary and liver. Environ Toxicol Pharmacol. 11: 119-26.

485 Hurd MW, Debruyne J, Straume M, Cahill GM. (1998). Circadian rhythms of locomotor 486 activity in zebrafish. Physiol Behav. 65: 465-72.

487 Idda ML, Bertolucci C, Vallone D, Gothilf Y, Sánchez-Vázquez FJ, Foulkes NS. (2012). 488 Circadian clocks: Lessons from fish. Prog Brain Res. 199: 41-57.

489 Košir R, Španinger K, Rozman D. (2013). Circadian events in human diseases and in 490 cytochrome P450-related drug metabolism and therapy. IUBMB Life. 65: 487-96.

491 Li Y, Li G, Wang H, Du J, Yan J. (2013). Analysis of a Gene Regulatory Cascade Mediating 492 Circadian Rhythm in Zebrafish. PLoS Comput Biol. 9: e1002940.

493 Mazzoccoli G, Pazienza V, Vinciguerra M. (2012). Clock genes and clock-controlled genes 494 in the regulation of metabolic rhythms. Chronobiol Int. 29: 227-51.

495 Nakata K, Tanaka Y, Nakano T, Adachi T, Tanaka H, Kaminuma T, Ishikawa T (2006). 496 Nuclear receptor-mediated transcriptional regulation in Phase I, II, and III xenobiotic 497 metabolizing systems. Drug Metab Pharmacokinet. 21: 437-57.

498 Pedrini-Martha V, Niederwanger M, Kopp R, Schnegg R, Dallinger R. (2016). Physiological, 499 diurnal and stress-related variability of cadmium-metallothionein gene expression in Land 500 snails. PLoS One. 11: e0150442.

501 Pfaffl MW. (2001). A new mathematical model for relative quantification in real-time RT502 PCR. Nucleic Acids Res. 29: e45. 
503

504

505

506

507

508

509

510

511

512

513

514

515

516

517

518

519

520

521

522

523

524

525

526

527

528

529

530

Pfaffl MW. (2004). Quantification strategies in real-time PCR. In Bustin SA, ed. A-Z of quantitative PCR. La Jolla: International University Line, pp. 87-112.

Portaluppi F, Smolensky MH, Touitou Y. (2010). Ethics and methods for biological rhythm research on animals and human beings. Chronobiol Int. 27: 1911-29.

Reinke H, Asher G. (2016). Circadian Clock Control of Liver Metabolic Functions. Gastroenterology. 150: 574-80.

Ribalta C, Sánchez-Hernández JC, Sole M. (2015). Hepatic biotransformation and antioxidant enzyme activities in Mediterranean fish from different habitat depths. Sci Total Environ. 532: 176-183.

Richardson VM, Santostefano MJ, Birnbaum LS. (1998). Daily Cycle of bHLH-PAS Proteins, Ah Receptor and Arnt, in Multiple Tissues of Female Sprague-Dawley Rats. Biochem Biophys Res Commun. 252: 225-31.

Ripperger JA, Schibler U. (2006). Rhythmic CLOCK-BMAL1 binding to multiple E-box motifs drives circadian Dbp transcription and chromatin transitions. Nat Genet. 38:

Ripperger JA, Shearman LP, Reppert SM, Schibler U. (2000). CLOCK, an essential pacemaker component, controls expression of the circadian transcription factor DBP. Genes Dev. 14: 679-89.

Sánchez-Vázquez FJ, Terry MI, Felizardo VO, Vera LM. (2011). Daily rhythms of toxicity and effectiveness of anesthetics (MS222 and eugenol) in zebrafish (Danio rerio). Chronobiol Int. 28: 109-17.

Untergasser A, Cutcutache I, Koressaar T, Ye J, Faircloth BC, Remm M, Rozen SG. (2012). Primer3-new capabilities and interfaces. Nucleic Acids Res. 40: e115.

Vatine G, Vallone D, Appelbaum L, Mracek P, Ben-Moshe Z, Lahiri K, Gothilf Y, Foulkes NS. (2009). Light directs zebrafish period2 expression via conserved D and E boxes. PLoS Biol. 7: e1000223.

Vera LM, Migaud H. (2016). Hydrogen peroxide treatment in Atlantic salmon induces stress and detoxification response in a daily manner. Chronobiol Int.: 1-13.

Vera LM, Montoya A, Sánchez-Vázquez FJ. (2013). Effectiveness of the anaesthetic MS-222 
531 in gilthead seabream, Sparus aurata: Effect of feeding time and day-night variations in 532 plasma MS-222 concentration and GST activity. Physiol Behav. 110-111: 51-7.

533 Vera LM, Negrini P, Zagatti C, Frigato E, Sánchez-Vázquez FJ, Bertolucci C. (2013). Light 534 and feeding entrainment of the molecular circadian clock in a marine teleost (Sparus aurata). 535 Chronobiol Int. 30: 649-61.

536 Vera LM, Ros-Sánchez G, García-Mateos G, Sánchez-Vázquez FJ. (2010). MS-222 toxicity 537 in juvenile seabream correlates with diurnal activity, as measured by a novel video-tracking 538 method. Aquaculture. 307: 29-34.

539 Whitmore D, Foulkes NS, Sassone-Corsi P. (2000). Light acts directly on organs and cells in 540 culture to set the vertebrate circadian clock. Nature. 404: 87-91.

541 Wuarin J, Schibler U. (1990). Expression of the liver-enriched transcriptional activator 542 protein DBP follows a stringent circadian rhythm. Cell. 63: 1257-66.

543 Xie F, Xiao P, Chen D, Xu L, Zhang B. (2012). miRDeepFinder: A miRNA analysis tool for 544 deep sequencing of plant small RNAs. Plant Mol Biol. 80: 75-84.

545 Zhang Y-KJ, Yeager RL, Klaassen CD. (2009). Circadian expression profiles of drug546 processing genes and transcription factors in mouse liver. Drug Metab Dispos. 37: 106-15. 
Table 1. Primers used for RT-qPCR.

\begin{tabular}{|c|c|c|c|c|c|c|}
\hline Gene & Forward sequence (5'-3') & Reverse sequence (5'-3') & Amplicon & $\mathbf{T a}$ & $\begin{array}{l}\text { Accession } \\
\text { number }\end{array}$ & Reference \\
\hline bmalla & GTCACAGACAAGTGCTACAGATGCG & TCCCTCCGCCATCTCCTGA & $261 \mathrm{bp}$ & $60^{\circ} \mathrm{C}$ & AF144690.1 & Amaral \& Johnston (2012) \\
\hline clockla & GGTTCAAGGACAGGGTTTACAGATG & GGTCGACCTCTGAGACTGCTGG & $280 \mathrm{bp}$ & $60^{\circ} \mathrm{C}$ & XM_017352431 & Amaral \& Johnston (2012) \\
\hline cryla & CTACAGGAAGGTCAAAAAGAACAGC & CTCCTCGAACACCTTCATGCC & $334 \mathrm{bp}$ & $60^{\circ} \mathrm{C}$ & AB042248.1 & Amaral \& Johnston (2012) \\
\hline per2 & GTGGAGAAAGCGGGCAGC & GCTCTTGTTGCTGCTTTCAGTTCT & $252 \mathrm{bp}$ & $60^{\circ} \mathrm{C}$ & XM_017357611.1 & Amaral \& Johnston (2012) \\
\hline hlfa & GCAGCTCTCACAATGGGATG & ATGGAGTCTGGGTCAATGGG & $106 \mathrm{bp}$ & $57^{\circ} \mathrm{C}$ & NM_001077334.2 & New design \\
\hline tefa & TGTCTGTCAAAGCAAGCCTG & GAAAAGGGCGAACTCCATCC & $73 \mathrm{bp}$ & $56^{\circ} \mathrm{C}$ & NM_131400.1 & New design \\
\hline$t e f b$ & GCTGTTGTTTTGGCTTGCTC & CGTGTCCAGGCATCATTAGC & $108 \mathrm{bp}$ & $56^{\circ} \mathrm{C}$ & NM_001020661.1 & New design \\
\hline dbpa & TGGAGGAGTTCTTGACGGAG & CTGTGTGCTCTGAGATGGGA & $92 \mathrm{bp}$ & $57^{\circ} \mathrm{C}$ & NM_001197060.1 & New design \\
\hline$d b p b$ & AGATGCTCGTCCCTGAAGAC & GTTCTTACAACGCCGACTCC & $59 \mathrm{bp}$ & $57^{\circ} \mathrm{C}$ & NM_001197062.1 & New design \\
\hline ahr2 & CAGATGCCTCCTTGACAACTCG & TCCAAGATCGAGGGTGGCTG & $165 \mathrm{bp}$ & $60^{\circ} \mathrm{C}$ & BC163711.1 & Li et al. (2013) \\
\hline smtb & TGCTCCAAATCTGGATCTTG & GCAGTCCTTCTTGCCCTTAC & $218 \mathrm{bp}$ & $55^{\circ} \mathrm{C}$ & EU918132.1 & Wu et al. (2012) \\
\hline$m t 2$ & AGACTGGAACTTGCAACTGTGGT & CAGCTGGAGCCACAGGAATT & $474 \mathrm{bp}$ & $55^{\circ} \mathrm{C}$ & NM_001131053.2 & Wu et al. (2012) \\
\hline $\operatorname{sod1}$ & GGTAATGTGACCGCTGATGC & АCTTTCCTCATTGCCACCCT & $150 \mathrm{bp}$ & $55^{\circ} \mathrm{C}$ & NM_131294.1 & New design \\
\hline cypla & AAACCAGTGGCAAGTCAACC & AAAACCAACACCTTCTCGCC & $126 \mathrm{bp}$ & $56^{\circ} \mathrm{C}$ & NM_131879.1 & New design \\
\hline cyp1d1 & TCGACCTGAACGGTTCCTCA & ACAACATTGCCCGTCTGGAG & $118 \mathrm{bp}$ & $60^{\circ} \mathrm{C}$ & NM_001007310.1 & New design \\
\hline cat & CCTGTTGAAGAAGCGGATCG & GGATGGGAAGTTGCCATTGG & $93 \mathrm{bp}$ & $57^{\circ} \mathrm{C}$ & AJ007505.1 & New design \\
\hline $\operatorname{gpx} 7$ & ACGGAGATGGTTCGGAAGTT & AGGTCTGAGTGTCAACAGGG & $85 \mathrm{bp}$ & $56^{\circ} \mathrm{C}$ & NM_001020501.1 & New design \\
\hline$g s r$ & GGGGTCATATCGTGGTGGAT & ATCAGGTGTCAGAAGGGCTC & $95 \mathrm{bp}$ & $57^{\circ} \mathrm{C}$ & NM_001020554.1 & New design \\
\hline gstt2 & GCTGTCCGACTCCTTTGATG & AATTTGTCCCTCAGGCGGTA & $57 \mathrm{bp}$ & $56^{\circ} \mathrm{C}$ & NM_200521.1 & New design \\
\hline gsttla & ATCTCATGGCTCAAAGGTCT & AAGACATGTTGAGATCCTCCA & $110 \mathrm{bp}$ & $60^{\circ} \mathrm{C}$ & NM_001327762.1 & Glisic et al. (2015) \\
\hline gstr1 & TAAAGAGAGATGTCCCAGACT & ACCGGCTTCTCCAGCCACT & 99 bp & $60^{\circ} \mathrm{C}$ & NM_001045060.2 & Glisic et al. (2015) \\
\hline mgst3a & TGTGTTGGGGATGATCTGGA & ACTCTCCCGGTGTCCACTGT & $144 \mathrm{bp}$ & $60^{\circ} \mathrm{C}$ & NM_213427.1 & New design \\
\hline$a b c b 4$ & TACTGATGATGCTTGGCTTAATC & TCTCTGGAAAGGTGAAGTTAGG & $159 \mathrm{bp}$ & $60^{\circ} \mathrm{C}$ & JQ014001 & Fisher et al. (2013) \\
\hline$a b c c 2$ & TCTGGACCCGTTTCAGACCT & CCTCCGACACCTCATGTTCA & $116 \mathrm{bp}$ & $60^{\circ} \mathrm{C}$ & ВC056740.1 & New design \\
\hline abcg2 & TCCAGCAGACACACGCTGAT & TGAGCACCCAGTGGAACTGA & $120 \mathrm{bp}$ & $60^{\circ} \mathrm{C}$ & NM_001042775 & New design \\
\hline sult2_st2 & TGCTGCTCCTCTGATCATCT & CACACCTTTATGCACCGAAT & $101 \mathrm{bp}$ & $60^{\circ} \mathrm{C}$ & BC142761.1 & New design \\
\hline bactin1 & CGAGCAGGAGATGGGAACC & CAACGGAAACGCTCATTGC & $102 \mathrm{bp}$ & $56^{\circ} \mathrm{C}$ & AF057040 & McCurley et al. (2008) \\
\hline slc $25 a 5$ & AAGCGACACCTCTCCAAGAA & TAGCATGTTGCACCTGAAGC & $153 \mathrm{bp}$ & $56^{\circ} \mathrm{C}$ & NM_173247 & New design \\
\hline$b 2 m$ & AGGATTGTCTGCTTGGCTCTCT & GGAGTGGAGACTTTCCCCTGTAC & $110 \mathrm{bp}$ & $56^{\circ} \mathrm{C}$ & NM_131163 & Tang et al. (2007) \\
\hline elf1a & СCTCTTGGTCGCTTTGCTGT & CTTGGTCTTGGCAGCCTTCT & $129 \mathrm{bp}$ & $57^{\circ} \mathrm{C}$ & AY422992.1 & New design \\
\hline$r p l 13$ & TCTGGAGGACTGTAAGAGGTATGC & AGACGCACAATCTTGAGAGCAG & $148 \mathrm{bp}$ & $56^{\circ} \mathrm{C}$ & NM_212784 & Tang et al. (2007) \\
\hline
\end{tabular}


549 Table 2. Parameters of the cosine function calculated by Cosinor analysis $(p<0.05)$ for diel 550 expression of clock genes in zebrafish exposed to a light-dark (LD) cycle or continuous 551 darkness (DD).

\begin{tabular}{llllll}
\hline Gene & Light regime & p value & Mesor & Amplitude & $\begin{array}{l}\text { Acrophase } \\
\text { (ZT/CT hours) }\end{array}$ \\
\hline \multirow{2}{*}{ bmal1 } & LD & $<0.01$ & $50.7 \pm 2.8$ & $41.9 \pm 4.9$ & $11: 11 \pm 00: 23$ \\
& DD & $<0.05$ & $72.4 \pm 7.0$ & $28.9 \pm 12.5$ & $10: 12 \pm 01: 59$ \\
clock1 & LD & $<0.01$ & $81.6 \pm 11.0$ & $87.4 \pm 19.6$ & $13: 31 \pm 00: 54$ \\
& DD & $<0.05$ & $85.1 \pm 7.8$ & $34.5 \pm 13.7$ & $14: 01 \pm 01: 52$ \\
cry1a & LD & $<0.01$ & $111.0 \pm 7.3$ & $105.0 \pm 13.1$ & $04: 00 \pm 00: 15$ \\
& DD & $<0.01$ & $91.5 \pm 8.3$ & $64.6 \pm 14.6$ & $02: 16 \pm 00: 55$ \\
per2 & LD & $<0.01$ & $104.6 \pm 10.4$ & $94.7 \pm 18.6$ & $05: 55 \pm 00: 46$ \\
& DD & $<0.05$ & $41.4 \pm 5.3$ & $19.41 \pm 9.4$ & $05: 10 \pm 02: 03$ \\
\hline
\end{tabular}

552

553 All parameters are expressed as the mean value \pm standard error (SE). 
555 Table 3. Parameters of the cosine function calculated by Cosinor analysis $(\mathrm{p}<0.05)$ for 556 transcription factors in zebrafish exposed to a light-dark (LD) cycle or continuous darkness 557 (DD).

\begin{tabular}{llllll}
\hline Gene & Light regime & p value & Mesor & Amplitude & $\begin{array}{l}\text { Acrophase (ZT/CT } \\
\text { hours) }\end{array}$ \\
\hline \multirow{2}{*}{$\boldsymbol{l} \boldsymbol{f} \boldsymbol{a}$} & LD & NS & - & - & - \\
& DD & NS & - & - & - \\
$\boldsymbol{t} \boldsymbol{f} \boldsymbol{a}$ & LD & $<0.01$ & $108.1 \pm 11.7$ & $98.5 \pm 20.6$ & $01: 19 \pm 01: 40$ \\
& DD & $<0.01$ & $71.0 \pm 4.7$ & $50.0 \pm 8.4$ & $23: 09 \pm 00: 58$ \\
$\boldsymbol{t} \boldsymbol{f} \boldsymbol{b}$ & LD & $<0.01$ & $55.4 \pm 5.9$ & $49.1 \pm 10.4$ & $22: 17 \pm 00: 51$ \\
& DD & $<0.01$ & $99.9 \pm 9.3$ & $62.3 \pm 16.3$ & $23: 56 \pm 01: 05$ \\
$\boldsymbol{d} \boldsymbol{b} \boldsymbol{p} \boldsymbol{a}$ & LD & $<0.01$ & $73.6 \pm 9.6$ & $84.2 \pm 16.9$ & $22: 58 \pm 00: 48$ \\
& DD & $<0.01$ & $95.9 \pm 8.4$ & $95.6 \pm 14.9$ & $23: 06 \pm 00: 40$ \\
$\boldsymbol{d} \boldsymbol{b} \boldsymbol{p} \boldsymbol{b}$ & LD & $<0.01$ & $67.4 \pm 9.6$ & $94.6 \pm 16.9$ & $21: 32 \pm 00: 42$ \\
& DD & $<0.01$ & $77.5 \pm 8.2$ & $96.2 \pm 14.6$ & $22: 39 \pm 00: 34$ \\
\multirow{2}{*}{$\boldsymbol{h} \boldsymbol{r} \boldsymbol{L}$} & LD & NS & - & - & - \\
& DD & $<0.05$ & $721.3 \pm 56.4$ & $249.5 \pm 100.7$ & $19: 23 \pm 01: 50$ \\
\hline
\end{tabular}

558

559 All parameters are expressed as the mean value \pm standard error (SE). NS=non significant. 
561 Table 4. Parameters of the cosine function calculated by Cosinor analysis $(p<0.05)$ for genes 562 coding detoxification enzymes and transporter proteins in zebrafish exposed to a light-dark 563 (LD) cycle or continuous darkness (DD).

\begin{tabular}{|c|c|c|c|c|c|}
\hline Gene & Light regime & $p$ value & Mesor & Amplitude & $\begin{array}{l}\text { Acrophase } \\
\text { (ZT/CT hours) }\end{array}$ \\
\hline \multirow{2}{*}{ smtb } & LD & NS & - & - & - \\
\hline & DD & NS & - & - & - \\
\hline \multirow{2}{*}{$m t 1$} & LD & NS & - & - & - \\
\hline & DD & NS & - & - & - \\
\hline \multirow{2}{*}{$m t 2$} & LD & NS & - & - & - \\
\hline & DD & NS & - & - & - \\
\hline \multirow{2}{*}{ sod1 } & LD & NS & - & - & - \\
\hline & DD & NS & - & - & - \\
\hline \multirow{2}{*}{ cypla } & LD & $<0.01$ & $51.5 \pm 9.7$ & $25.0 \pm 8.6$ & $21: 30 \pm 01: 26$ \\
\hline & DD & $<0.01$ & $63.5 \pm 5.1$ & $29.1 \pm 9.3$ & $21: 58 \pm 01: 03$ \\
\hline \multirow{2}{*}{ cyp1d1 } & LD & NS & - & - & - \\
\hline & DD & NS & - & - & - \\
\hline \multirow{2}{*}{ cat } & LD & NS & - & - & - \\
\hline & DD & NS & - & - & - \\
\hline \multirow{2}{*}{$\operatorname{gpx} 7$} & LD & NS & - & - & - \\
\hline & DD & NS & - & - & - \\
\hline \multirow[b]{2}{*}{$g s r$} & $\mathrm{LD}$ & NS & - & - & - \\
\hline & DD & NS & - & - & - \\
\hline \multirow{2}{*}{ gstt2 } & LD & NS & - & - & - \\
\hline & DD & NS & - & - & - \\
\hline \multirow{2}{*}{ gstt1a } & LD & NS & - & - & - \\
\hline & DD & NS & - & - & - \\
\hline \multirow{2}{*}{ gstr1 } & $\mathrm{LD}$ & NS & - & - & - \\
\hline & DD & $<0.01$ & $658.7 \pm 55.6$ & $334.7 \pm 100.3$ & $20: 11 \pm 01: 13$ \\
\hline \multirow{2}{*}{ mgst3a } & LD & NS & - & - & - \\
\hline & DD & $<0.01$ & $489.0 \pm 32.6$ & $166.2 \pm 59.1$ & $20: 19 \pm 01: 31$ \\
\hline \multirow{2}{*}{$a b c b 4$} & LD & $<0.01$ & $692.0 \pm 62.9$ & $354.0 \pm 110.5$ & $00: 03 \pm 01: 19$ \\
\hline & DD & $<0.01$ & $533.8 \pm 28.2$ & $170.7 \pm 50.6$ & $23: 10 \pm 01: 11$ \\
\hline \multirow{2}{*}{$a b c b 5$} & $\mathrm{LD}$ & NS & - & - & - \\
\hline & DD & NS & - & - & - \\
\hline \multirow{2}{*}{$a b c c 2$} & $\mathrm{LD}$ & NS & - & - & - \\
\hline & DD & NS & - & - & - \\
\hline \multirow{2}{*}{ abcg2 } & $\mathrm{LD}$ & NS & - & - & - \\
\hline & DD & $<0.05$ & $152.4 \pm 17.3$ & $71.1 \pm 31.2$ & $21: 13 \pm 02: 05$ \\
\hline \multirow{2}{*}{ sult2_st2 } & LD & NS & - & - & - \\
\hline & DD & $<0.05$ & $438.0 \pm 42.0$ & $183.7 \pm 74.6$ & $19: 50 \pm 01: 52$ \\
\hline
\end{tabular}

564

565 All parameters are expressed as the mean value \pm standard error (SE). NS=non significant. 
Figure 1. Mean waveforms representing the average diel profile of locomotor activity for each experimental tank ( $\mathrm{n}=7$ fish) under an LD cycle The height of each point in the waveform represents the mean of infrared light beam interruptions for each period of $10 \mathrm{~min}$ during the $24 \mathrm{~h}$ cycle. The white and black bars at the top of the graph indicate the light and dark periods, respectively. Data represent the mean (black area) + SE (dashed line). ZT, zeitgeber time.

Figure 2. Relative expression of clock genes in the liver of zebrafish kept in LD (A) and DD (B). The white, grey and black bars at the top of the graph indicate the light, subjective day and dark periods, respectively. Data are shown as the mean \pm SE. $(n=7)$. Superscript letters indicate statistically significant differences (ANOVA I, $\mathrm{p}<0.05$ ). The continuous black line represents the sinusoidal function determined by Cosinor analysis. ZT, zeitgeber time. CT, circadian time.

Figure 3. Relative expression of PAR bZIP and (bHLH)-PAS transcription factors in the liver of zebrafish kept in LD. The white and black bars at the top of the graph indicate the light and dark periods, respectively. Graph definitions as given in Figure 2.

Figure 4. Relative expression of PAR bZIP and (bHLH)-PAS transcription factors in the liver of zebrafish kept in DD. The grey and black bars at the top of the graph indicate the subjective day and night, respectively. Graph definitions as given in Figure 2.

Figure 5. Relative expression of Phase I detoxification enzymes in the liver of zebrafish kept in LD (A) and DD (B). Graph definitions as given in Figure 2.

Figure 6. Relative expression of Phase II detoxification enzymes and ABC transporters in the liver of zebrafish kept in LD (A) and DD (B). Graph definitions as given in Figure 2.

Figure 7. Acrophase map for the statistically significant parameters analyzed in LD (A) and 
592 DD, respectively. The SE is indicated by the lateral bars. White and black bars above the 593 graph represent light and darkness, respectively.

594

595 Supplementary Figure 1. Relative expression of detoxification enzymes not showing daily 596 or circadian rhythmicity in the liver of zebrafish kept in LD (A) and DD (B). Data are shown 597 as the mean \pm SE. $(n=7)$. Superscript letters indicate statistically significant differences 598 (ANOVA I, $\mathrm{p}<0.05$ ). The continuous black line represents the sinusoidal function determined 599 by Cosinor analysis. ZT, zeitgeber time. CT, circadian time.

600 
Figure1

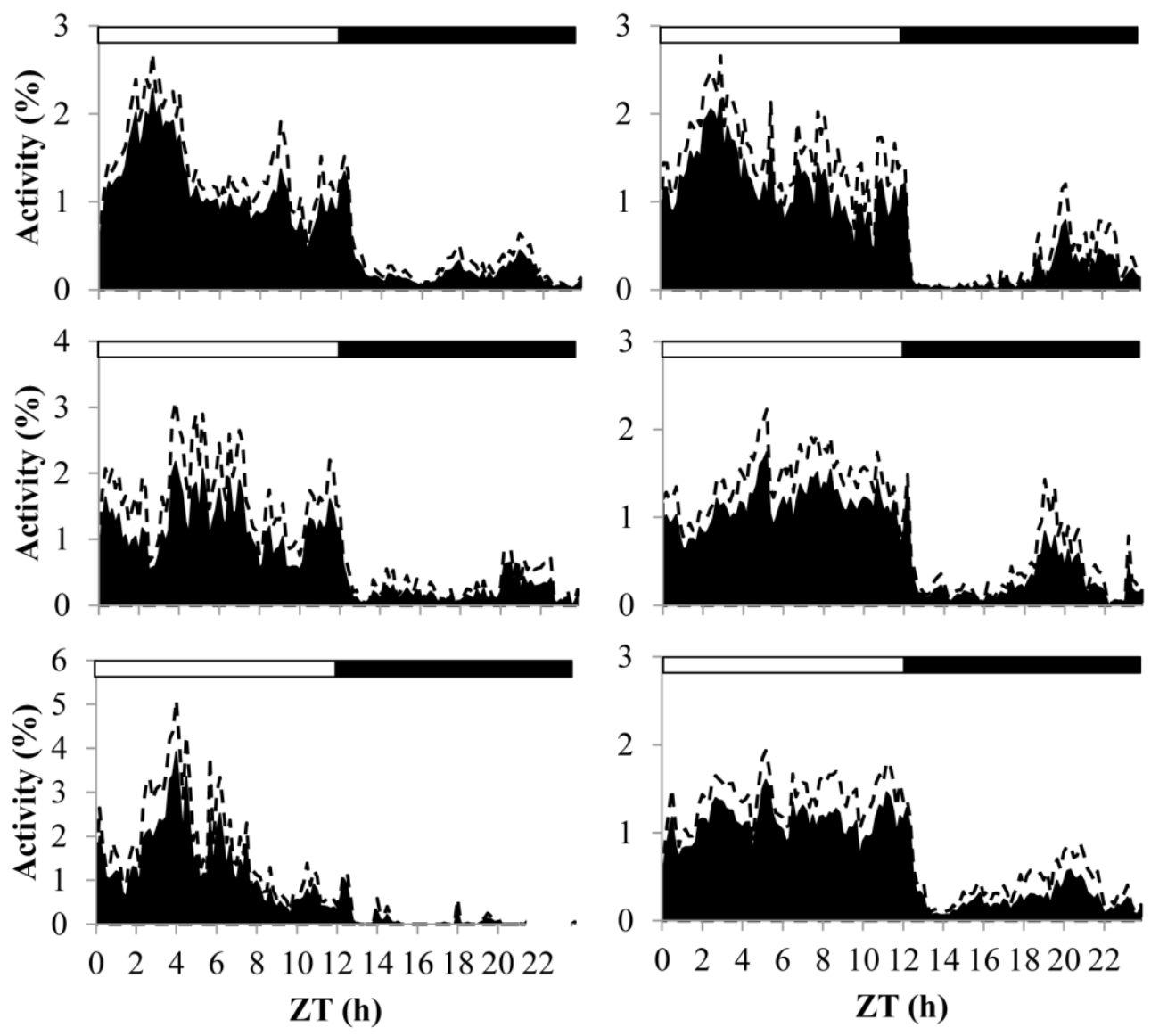

601

602 
Figure 2

A
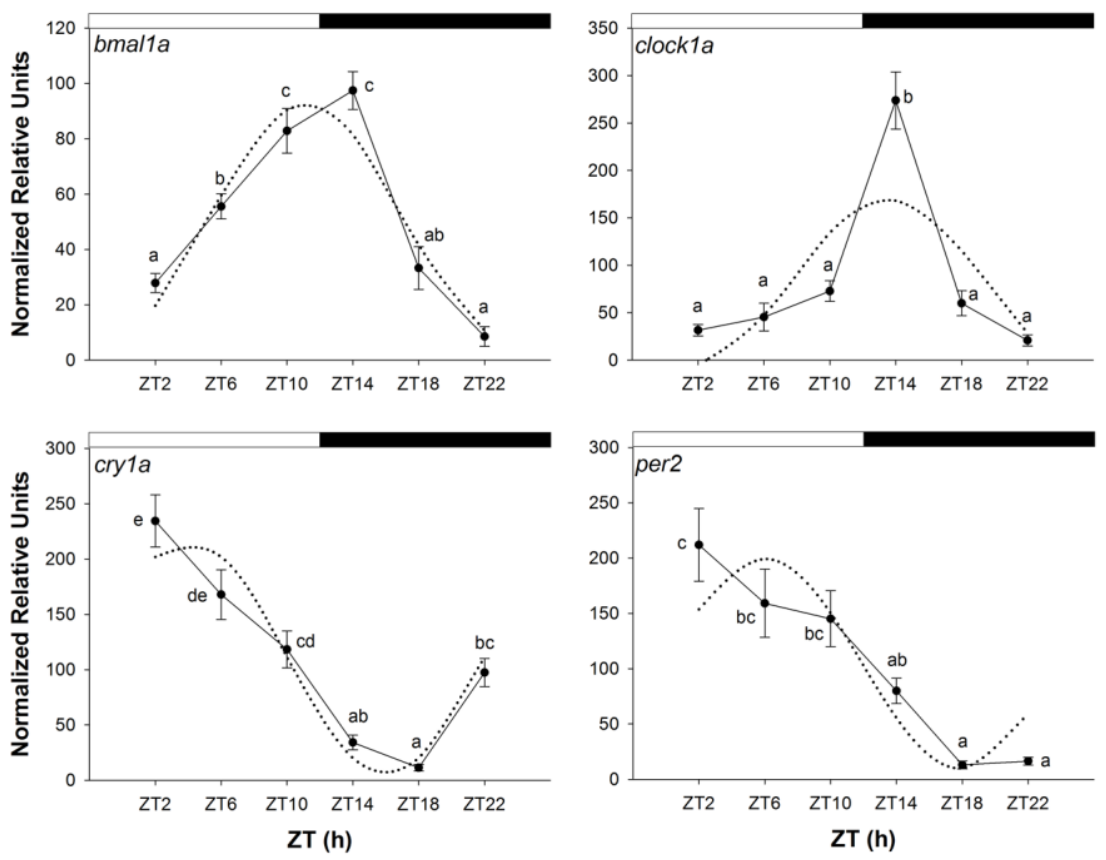

B
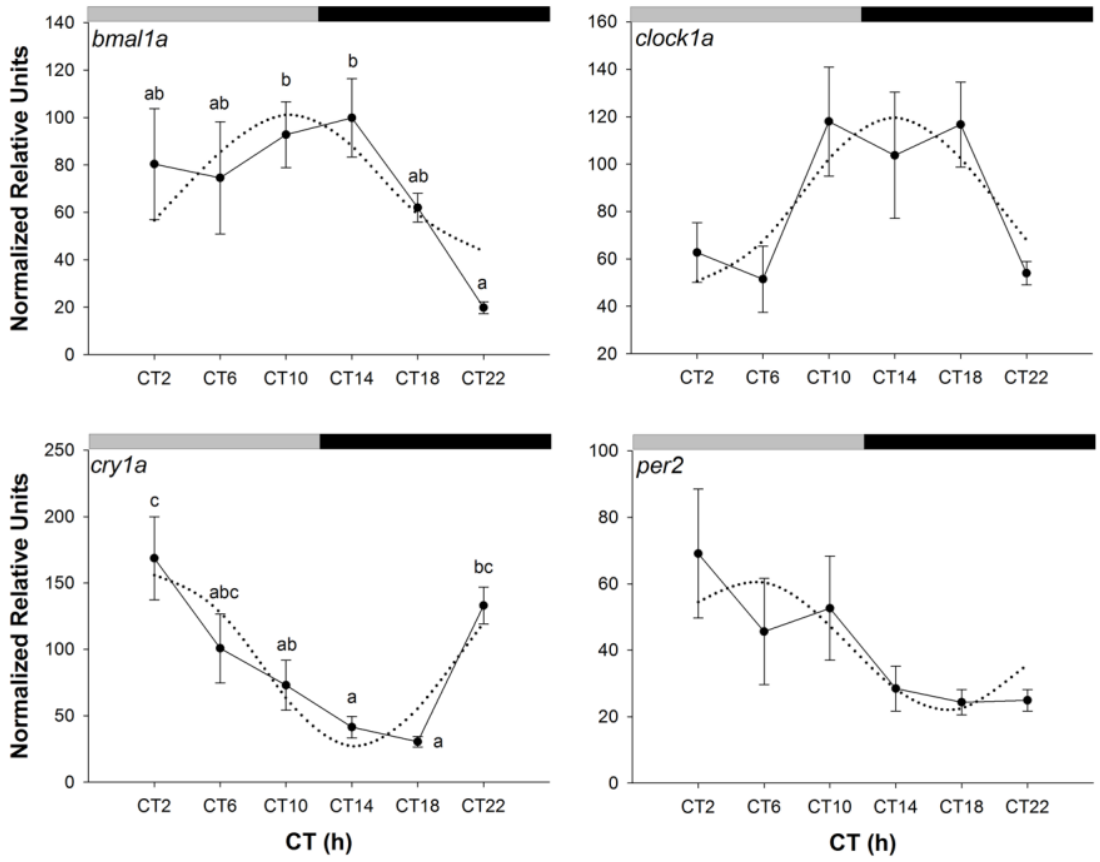

603 
Figure 3
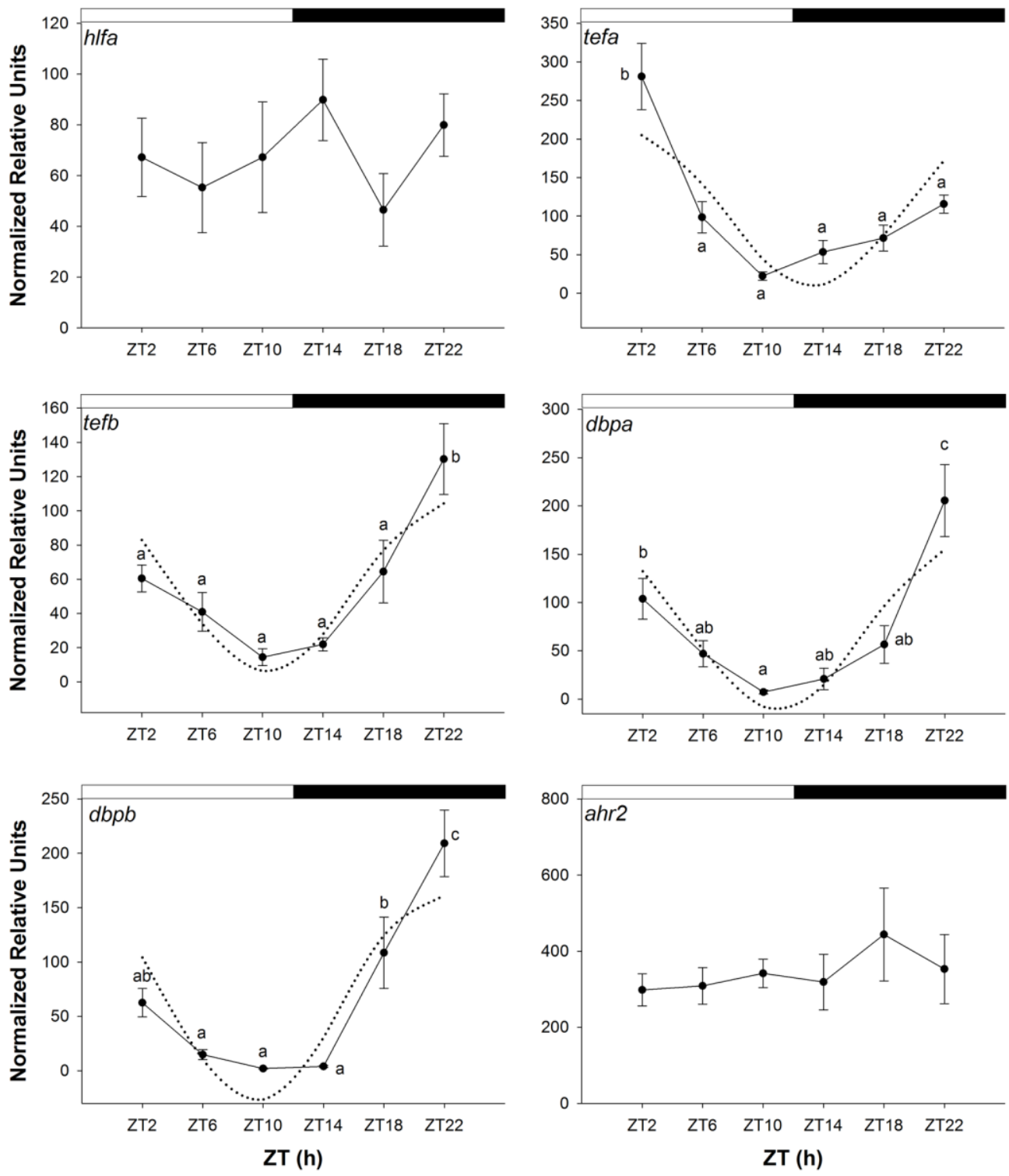

605 
Figure 4
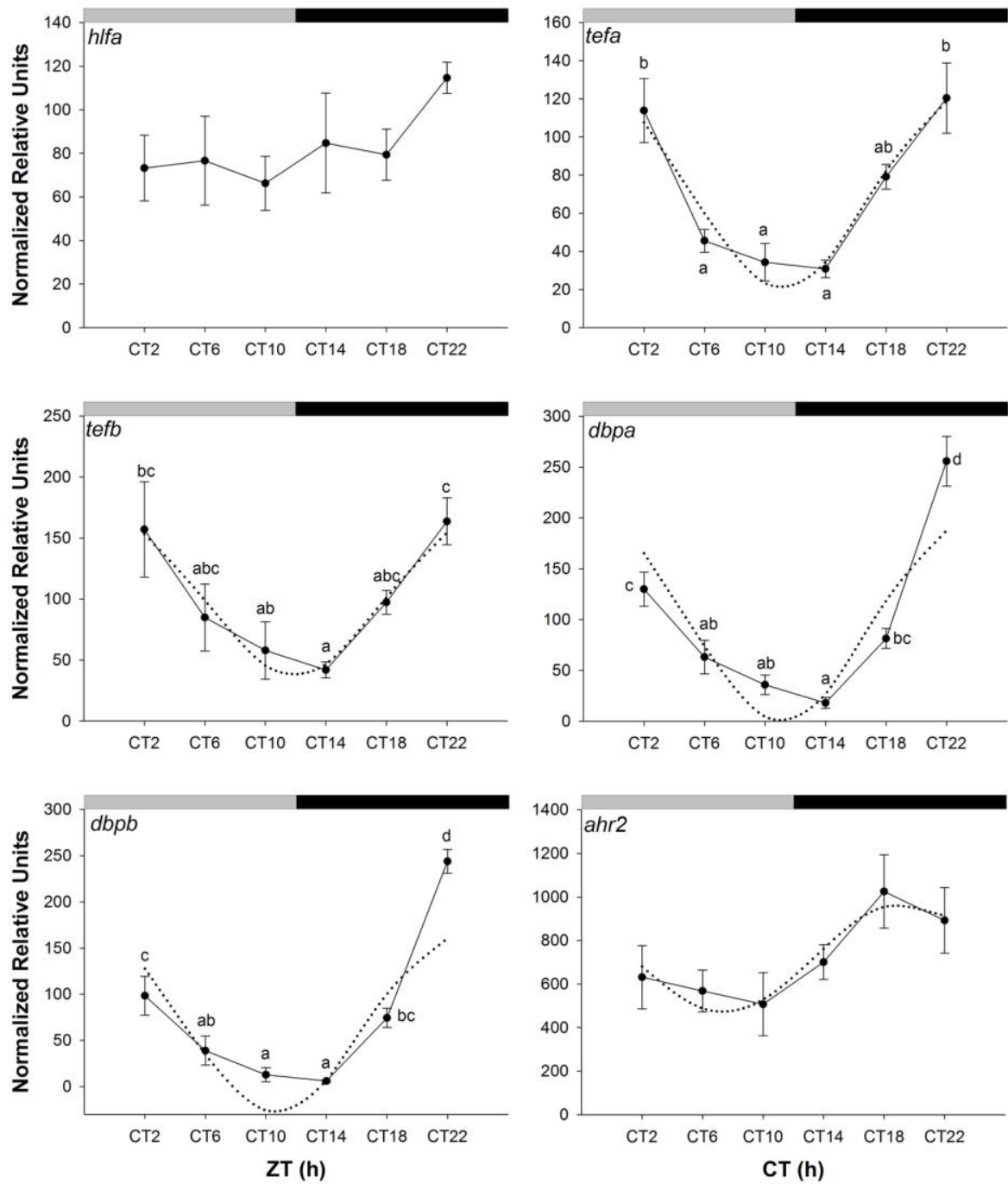

607

608 
Figure 5
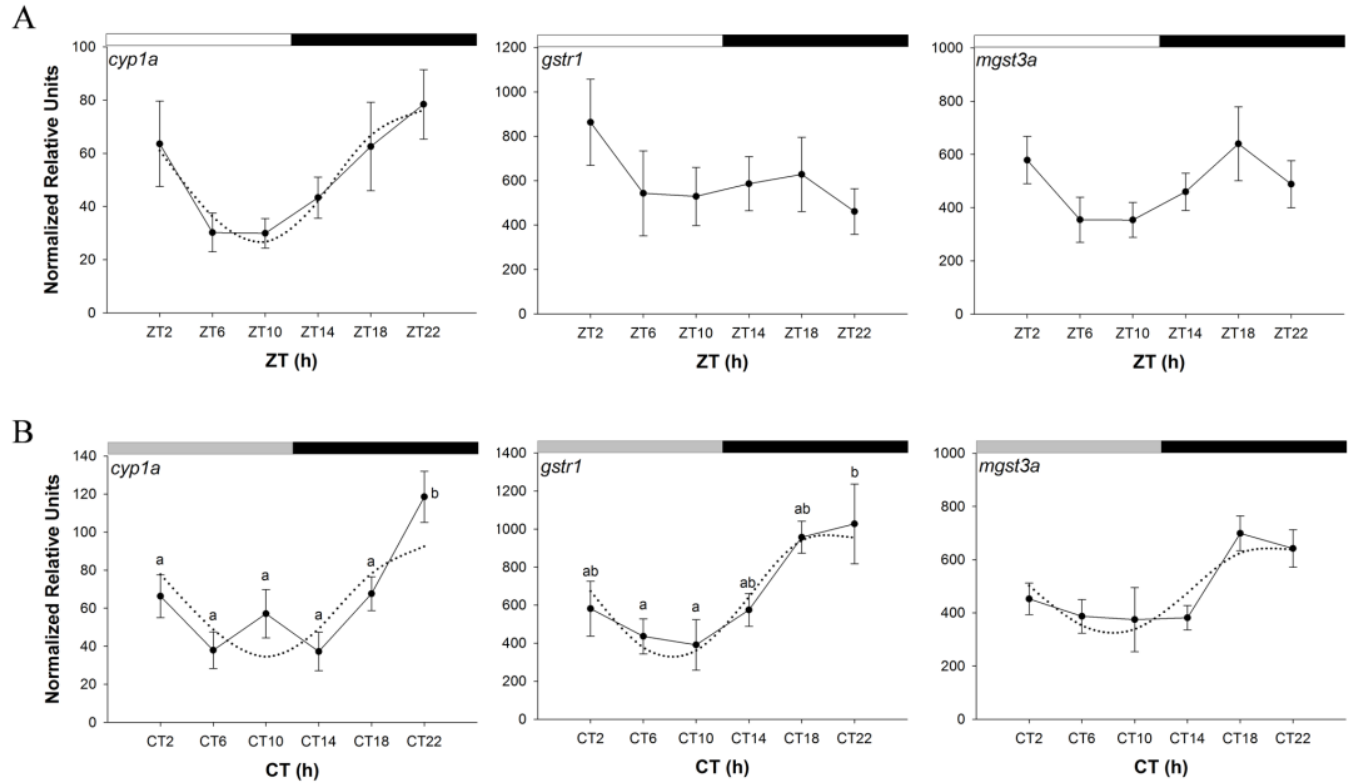

609

610 
Figure 6

A
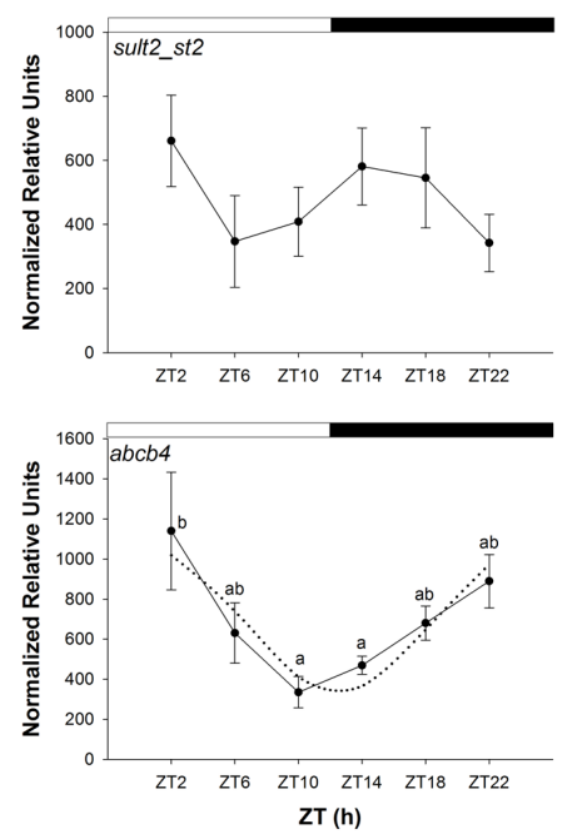

B
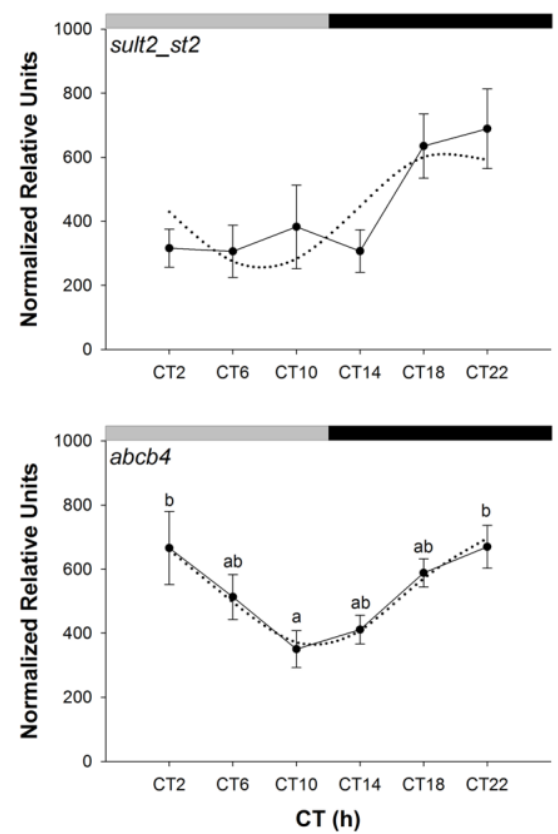
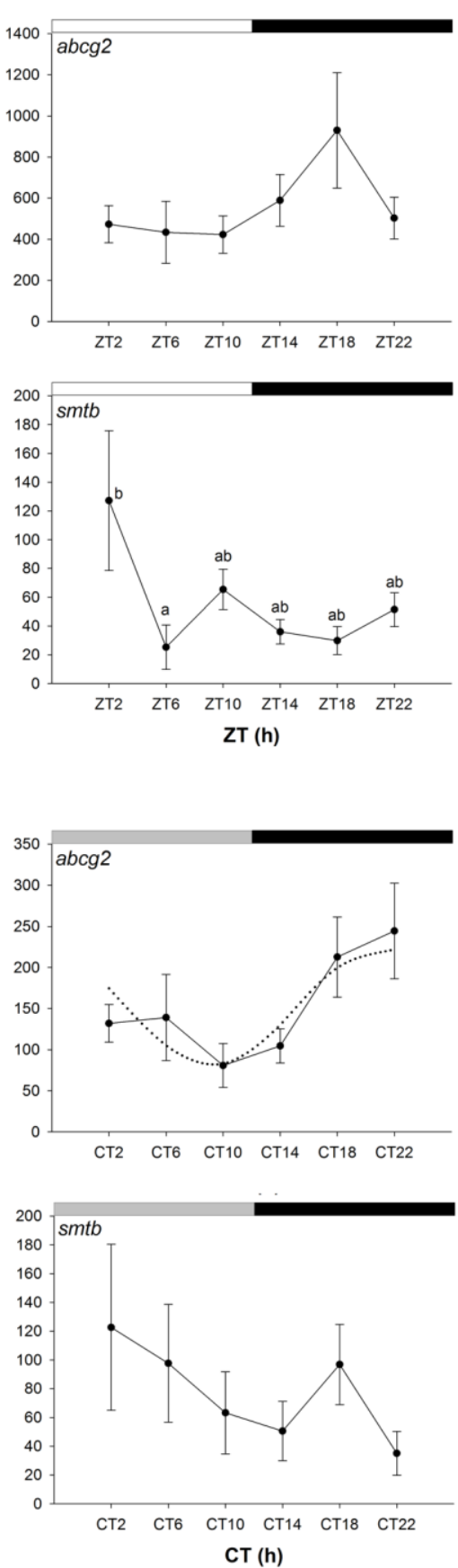

611

612 
Figure 7

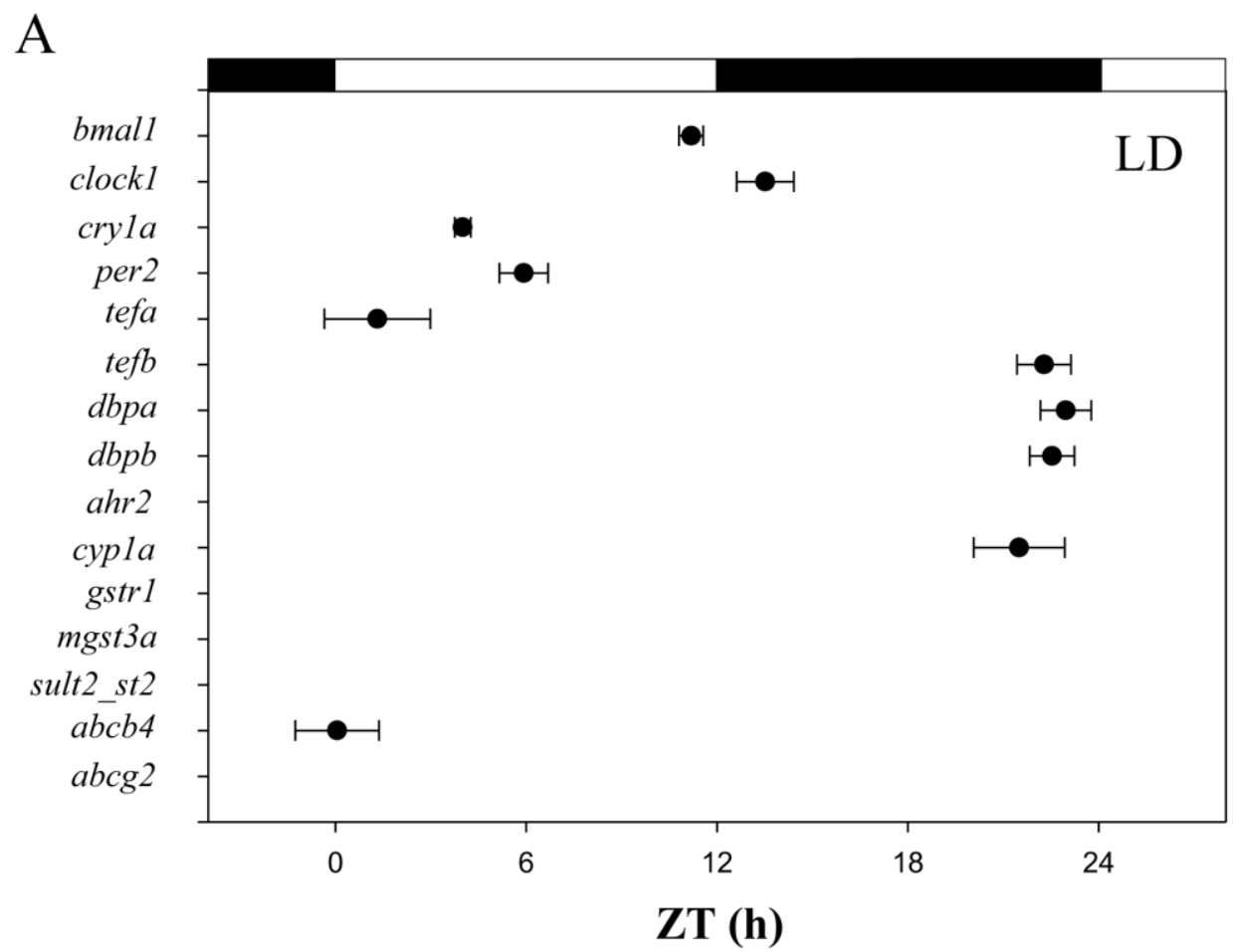

B

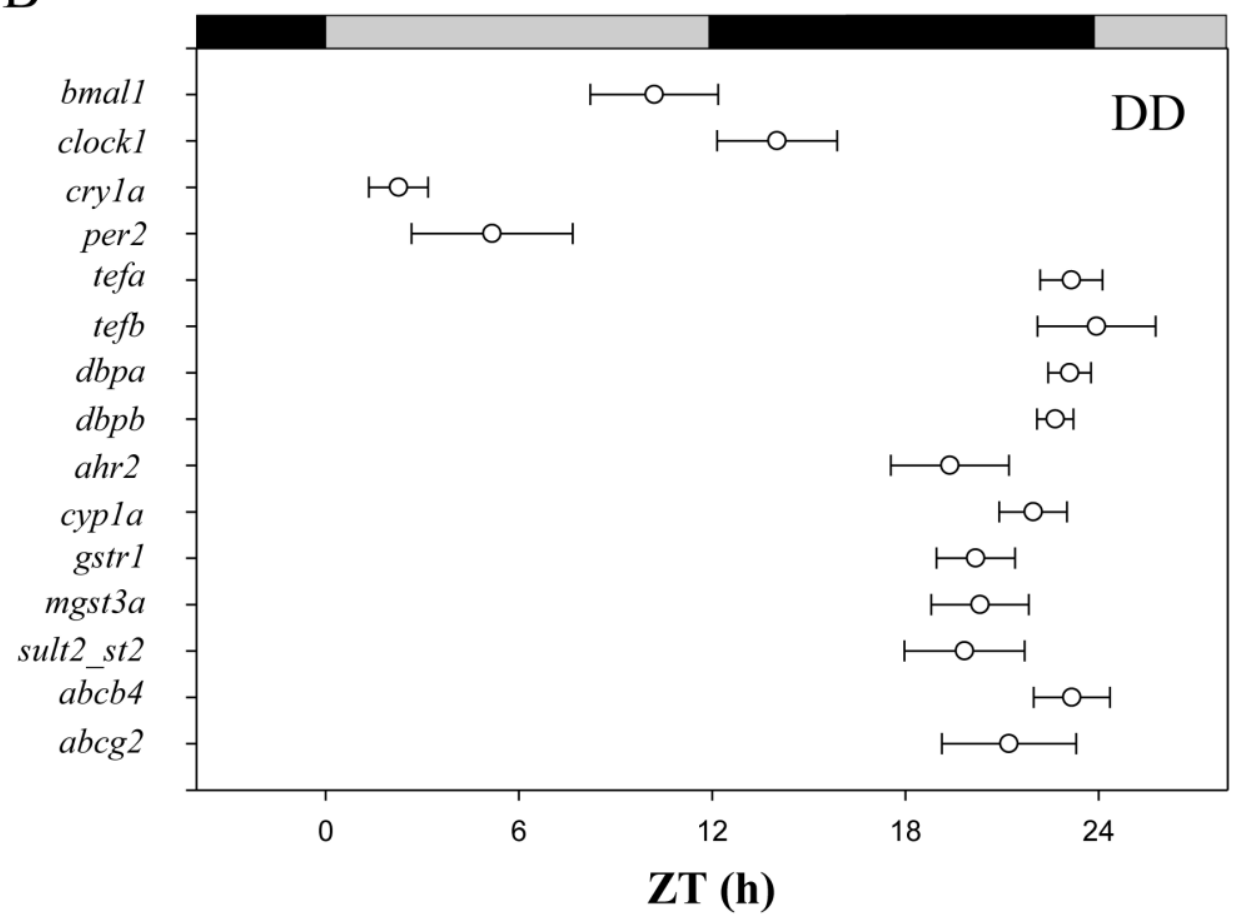

613

614

615

616 
618
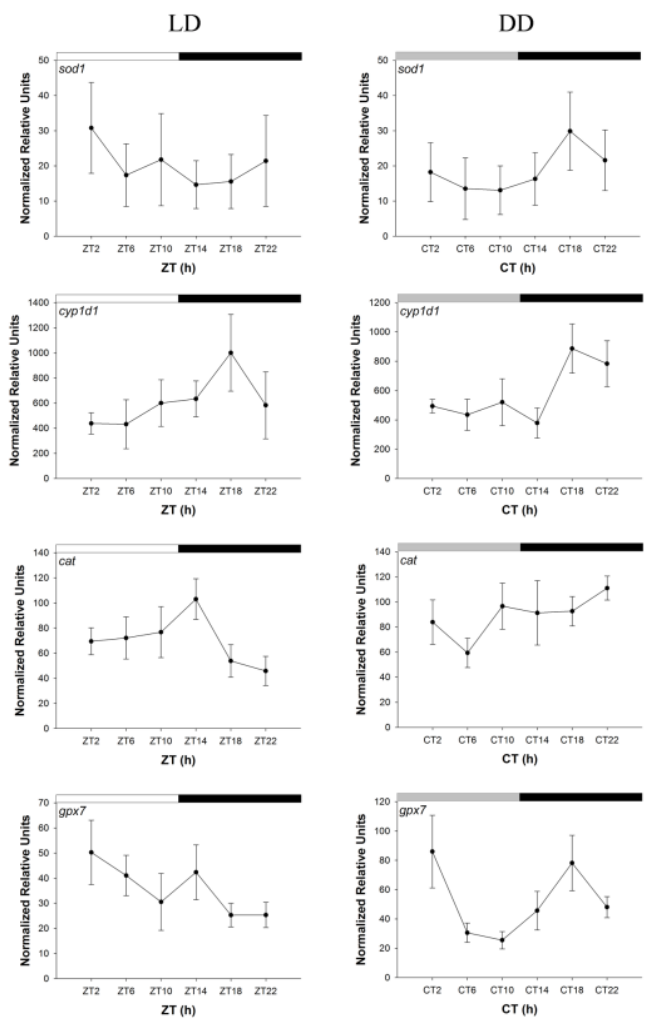

LD

DD
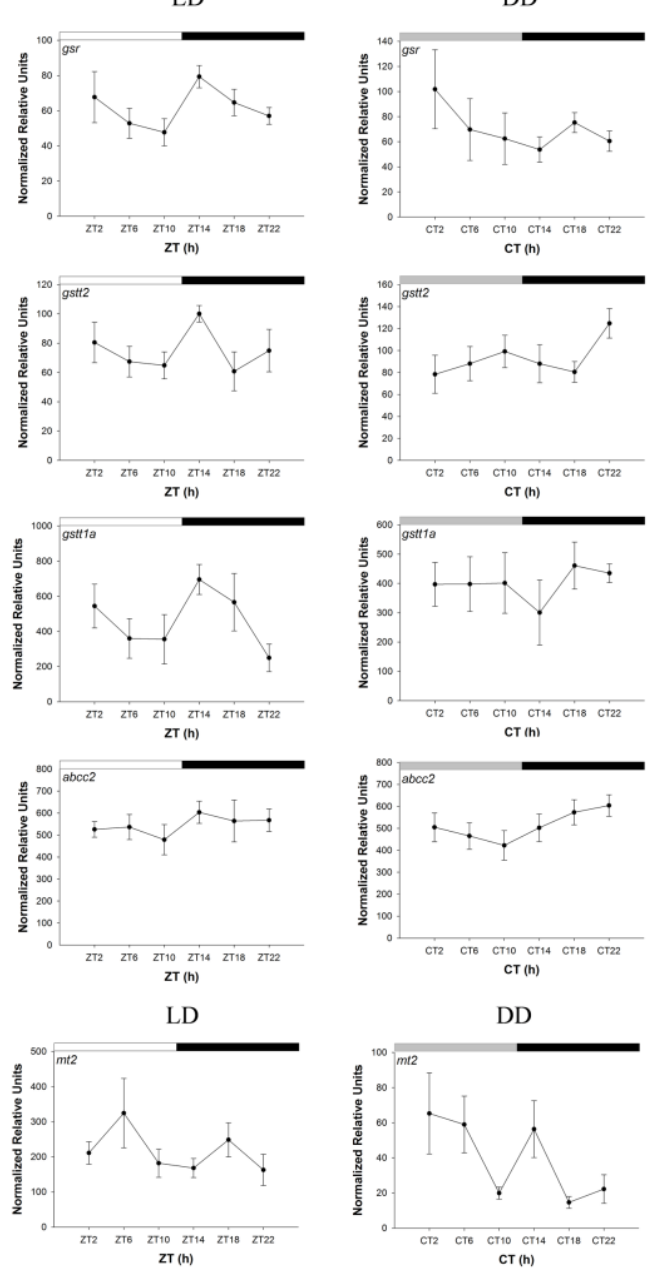

DD

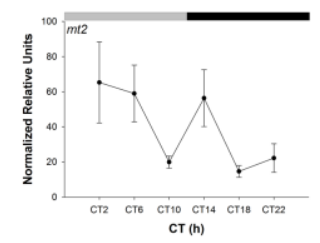


Detoxification genes

\begin{tabular}{|c|c|c|c|c|}
\hline Gene name & Gene abbreviation & Function & Gene Ontology (GO) Terms & Source \\
\hline \multirow[t]{2}{*}{ metallothionein-B-like } & smtb & Binds heavy metals & Molecular function - metal ion binding & UniProtKB-KW \\
\hline & & & Biological process - angiogenesis & ZFIN \\
\hline metallothionein 2 & $m+2$ & Binds heavy metals & Molecular function - metal ion binding & ZFIN \\
\hline \multirow[t]{7}{*}{ superoxide dismutase 1} & sod1 & Major antioxidant defense against the superoxide anion, catalysing & Molecular function - copper ion binding & GO_Central \\
\hline & & & Molecular function - superoxide dismutase activity & ZFIN \\
\hline & & & Molecular function - zinc ion binding & GO_Central \\
\hline & & & Biological process - neuron cellular homeostasis & ZFIN \\
\hline & & & Biological process - response to metal ion & ZFIN \\
\hline & & & Biological process - response to methylmercury & ZFIN \\
\hline & & & Biological process - response to xenobiotic stimulus & ZFIN \\
\hline \multirow[t]{8}{*}{ cytochrome $P 450$, family 1 , subfamily $A$} & cyp1a & Oxidation of hydrophobic substrates in phase I metabolism & Molecular function - aromatase activity & UniProtKB-EC \\
\hline & & & Molecular function - heme binding & InterPro \\
\hline & & & Molecular function - iron ion binding & InterPro \\
\hline & & & Molecular function - monooxygenase activity & GO_Central \\
\hline & & & Biological process - cellular aromatic compound metal & IZFIN \\
\hline & & & Biological process - cellular response to organic cyclic & CZFIN \\
\hline & & & Biological process - cellular response to xenobiotic stir & IZFIN \\
\hline & & & Biological process - response to xenobiotic stimulus & ZFIN \\
\hline \multirow[t]{4}{*}{ cytochrome P450, family 1, subfamily D, polypep } & t cyp1d1 & Oxidation of hydrophobic substrates in phase I metabolism & Molecular function - aromatase activity & UniProtKB-EC \\
\hline & & & Molecular function - heme binding & InterPro \\
\hline & & & Molecular function - iron ion binding & InterPro \\
\hline & & & Molecular function - testosterone 6-beta-hydroxylase a & ZFIN \\
\hline \multirow[t]{6}{*}{ catalase } & cat & Protects cells from the toxic effects of hydrogen peroxide, catalysi & ir Molecular function - catalase activity & GO_Central \\
\hline & & & Molecular function - heme binding & GO_Central \\
\hline & & & Molecular function - metal ion binding & UniProtKB-KW \\
\hline & & & Biological process - hydrogen peroxide catabolic proce & EGO_Central \\
\hline & & & Biological process - response to copper ion & \\
\hline & & & Biological process - response to hydrogen peroxide & GO_Central \\
\hline \multirow[t]{2}{*}{ glutathione peroxidase 7} & gpx7 & Cell protection from oxidative damage by reducing hydroperoxides & Molecular function - glutathione peroxidase activity & InterPro \\
\hline & & & Biological process - response to oxidative stress & InterPro \\
\hline \multirow[t]{5}{*}{ glutathione reductase } & gsr & Cell protection against oxidative damage, increasing the level of re & (Molecular function - flavin adenine dinucleotide binding & InterPro \\
\hline & & & Molecular function - glutathione-disulfide reductase act & t InterPro \\
\hline & & & Molecular function - NADP binding & InterPro \\
\hline & & & Biological process - cell redox homeostasis & InterPro \\
\hline & & & Biological process - glutathione metabolic process & InterPro \\
\hline glutathione $S$-transferase theta 2 & gstt2 & Xenobiotic detoxification by catalysis of the nucleophilic attack of th & h Molecular function - glutathione transferase activity & UniProt-GOA \\
\hline glutathione S-transferase theta 1a & gstt1a & Xenobiotic detoxification by catalysis of the nucleophilic attack of th & $\mathrm{h}$ Molecular function - glutathione transferase activity & ZFIN \\
\hline glutathione S-transferase rho & gstr1 & Xenobiotic detoxification by catalysis of the nucleophilic attack of th & h Molecular function - glutathione transferase activity & ZFIN \\
\hline \multirow[t]{2}{*}{ microsomal glutathione S-transferase $3 a$} & mgst3a & Xenobiotic detoxification by catalysis of the nucleophilic attack of th & h Molecular function - glutathione peroxidase activity & GO_Central \\
\hline & & & Molecular function - glutathione transferase activity & GO_Central \\
\hline \multirow{5}{*}{ ATP-binding cassette, sub-family $B$, member 4} & $a b c b 4$ & Cellular toxicant transporter & Molecular function - ATPase-coupled protein transmen & IZFIN \\
\hline & & & Molecular function - ATP binding & UniprotKB-KW \\
\hline & & & Molecular function - efflux transmembrane transporter & ZFIN \\
\hline & & & Molecular function - toxin transporter activity & ZFIN \\
\hline & & & Biological process - response to toxic substance & ZFIN \\
\hline \multirow[t]{4}{*}{ ATP-binding cassette, sub-family C, member 2} & $a b c c 2$ & Cellular toxicant transporter & Molecular function - ATPase activity, coupled to transtr & rGO_Central \\
\hline & & & Molecular function - ATP binding & UniprotKB-KW \\
\hline & & & Molecular function - organic anion transmembrane trar & r InterPro \\
\hline & & & Biological process - transmembrane transport & GO_Central \\
\hline \multirow[t]{4}{*}{ ATP-binding cassette, sub-family G, member 2} & abcg2 & Cellular toxicant transporter & Molecular function - ATPase activity, coupled to transm & rGO_Central \\
\hline & & & Molecular function - ATP binding & UniprotKB-KW \\
\hline & & & Biological process - cholesterol efflux & GO_Central \\
\hline & & & Biological process - drug transmembrane transport & GO_Central \\
\hline \multicolumn{2}{|c|}{ sulfotransferase family 2, cytosolic sulfotransfera sult2_st2 } & Phase II detoxifying enzyme mediating sulfate conjugation of $h$ & Molecular function - sulfotransferase activity & ZFIN \\
\hline
\end{tabular}


Details of reference genes used for qPCR. Expression stability was assessed according to BestKeeper (Pfaffl et al., 2004) calculated on corrected Ct values.

$623 *$, genes used to normalise expression.

\begin{tabular}{|c|c|c|c|c|c|c|c|c|c|}
\hline \multicolumn{6}{|c|}{ Data of candidate reference genes $(n=40)$} & \multicolumn{4}{|c|}{ Circadian Time } \\
\hline Genes & Efficiency & $\begin{array}{c}\text { GeoMean } \\
{[C t]}\end{array}$ & $\begin{array}{c}\text { Ct Range } \\
{[\operatorname{Min}, \operatorname{Max}]}\end{array}$ & $\begin{array}{c}\text { SD } \\
{[ \pm C t]}\end{array}$ & $\begin{array}{c}\mathrm{SD} \\
{[ \pm \text { corrected }} \\
C t]\end{array}$ & $\begin{array}{c}\text { GeoMean } \\
{[C t]}\end{array}$ & $\begin{array}{c}\text { Ct Range } \\
{[\operatorname{Min}, \operatorname{Max}]}\end{array}$ & $\begin{array}{c}\text { SD } \\
{[ \pm C t]}\end{array}$ & $\begin{array}{c}\text { SD } \\
{[ \pm \text { corrected }} \\
C t]\end{array}$ \\
\hline$b 2 m$ & 1.99 & 22.00 & {$[20.4,23.7]$} & 1.02 & 1.79 & 21.26 & {$[18.4,23.6]$} & 1.21 & 3.61 \\
\hline elf-1a & 1.96 & 20.12 & {$[18.7,22.7]$} & 0.84 & 2.99 & 20.14 & {$[18.3,23.0]$} & 0.92 & 3.39 \\
\hline rpl13* & 1.97 & 16.66 & {$[16.0,18.6]$} & 0.53 & 0.33 & 16.61 & {$[15.6,18.0]$} & 0.48 & 0.35 \\
\hline $\operatorname{slc} 25 a^{*}$ & 1.91 & 16.83 & {$[15.4,18.7]$} & 0.72 & 0.74 & 16.60 & {$[15.4,19.8]$} & 0.90 & 0.99 \\
\hline$b$-actin & 1.97 & 24.09 & {$[20.0,26.6]$} & 1.24 & 4.55 & 23.61 & {$[19.1,25.8]$} & 1.51 & 7.97 \\
\hline $\begin{array}{l}\text { BestKeep } \\
\text { Normal }\end{array}$ & $\begin{array}{l}\text { gene index } \\
\text { ation factor } \\
(\mathbf{n}=2)\end{array}$ & $\begin{array}{c}\text { Iculated on } \mathrm{c} \\
\mathbf{1 . 7 1}\end{array}$ & $\begin{array}{l}\text { ted } \mathrm{Ct} \text { values } \mathrm{f} \\
{[\mathbf{0 . 4 6}, \mathbf{2 . 9 7}]}\end{array}$ & ne most s & $\begin{array}{l}\text { e reference gen } \\
\mathbf{0 . 5 8}\end{array}$ & 1.88 & {$[0.66,3.29]$} & - & 0.70 \\
\hline
\end{tabular}

